\title{
La expansión de las funciones del Consejo de Seguridad de Naciones Unidas: problemas y posibles soluciones*
}

\section{The Expansion of the Functions of the UN Security Council: Problems and Possible Solutions}

\section{Soledad Torrecuadrada García-Lozano**}

SUMARIO: I. Introducción. II. Los nuevos problemas: la originalidad de las medidas adoptadas por el Consejo de Seguridad y la falta de control en la aplicación. III. Las posibles soluciones: el control de legalidad de las decisiones del Consejo de Seguridad. IV. Conclusiones.

* Artículo recibido el 27 de julio de 2011 y aprobado para publicación el 28 de septiembre de 2011.

** Profesora de Derecho Internacional Público y Relaciones Internacionales en la Facultad de Derecho de la Universidad Autónoma de Madrid (España); doctora en Derecho por esta misma Universidad; M. A. en Relaciones Internacionales por el Instituto Universitario de Investigación Ortega y Gasset de Madrid, adscrito a la Universidad Complutense de Madrid, y Diploma del Centre for Studies and Research in International Law and International Relations de la Academia de Derecho Internacional de La Haya (Holanda). 
RESUmen: En los últimos años, el Consejo de Seguridad ha adoptado decisiones de difícil encaje en el Capítulo VII de la Carta, en la que aquel órgano principal formalmente las fundamenta. La inexistencia de controles de legalidad sobre la calificación de las situaciones, de las medidas adoptadas o de su aplicación, suscita cuestiones jurídicas interesantes. Para resolverlas, se indican las posibles soluciones a la situación actual.

Palabras clave: Consejo de Seguridad, competencias, Carta de Naciones Unidas, órganos subsidiarios, control de legalidad, aplicación, resoluciones legislativas, derecho de veto, control judicial.

ABSTRACT: In recent years, the Security Council has taken difficult decisions to fit in Chapter VII of the Charter, in which the main body that formally founded. The absence of legal controls on the identification of situations, the measures or their implementation, raises interesting legal issues. To resolve them, indicating the possible solutions to the current situation

Descriptors: Security Council, Competencies, UN Charter, Subsidiary organs, Control of legality, Implementation, Legislative resolutions, Right of veto, Judicial control.

RÉSUMÉ: Dans les dernières années, le Conseil de sécurité a pris des décisions de difficil fondamentartion dans le chapitreVII de la Charte, même si formalement étaient fondées sur lui. L'absence de contrôle juridique sur l'identification de situations, les mesures ou leur application, soulève d'intéressantes questions juridiques. Pour les résoudre, en indiquant les solutions possibles à la situation actuelle.

Mots-Clés: Conseil de sécurité, Les compétences, La Charte des Nations Unies, Les organes subsidiaires, Contrôle de légalité, Application, Les résolutions législatives, Le droit de veto, Le contrôle judiciaire. 


\section{INTRODUCCIÓN}

En los primeros días de agosto se han cumplido veintiún años de la invasión y posterior anexión de Kuwait por parte de Iraq, ${ }^{1}$ que consiguió despertar a este órgano principal de las Naciones Unidas (en adelante NU) desde su nacimiento. En el verano de 1990, por este motivo, se iluminaban nuestras esperanzas en que el responsable principal dentro de la organización del mantenimiento de la paz y la seguridad internacionales, se convirtiera en el órgano que la sociedad internacional, transformada desde 1945, precisaba.

Lo que no imaginamos entonces era que el Consejo de Seguridad pasara en muy poco tiempo de la congelación que caracterizó su comportamiento durante los primeros cuarenta y cinco años de su existencia hasta el recalentamiento que le ha caracterizado a partir de entonces. ${ }^{2}$ Así, la actividad de este órgano principal durante el periodo comprendido desde el 2 de agosto de 1990 hasta la actualidad puede calificarse de efervescente o hiperactiva, tanto desde una perspectiva cuantitativa como cualitativa. En el primero de los sentidos, comparando el número de resoluciones adoptadas hasta la fecha recién indicada con las que han visto la luz desde entonces hasta nuestros días. Los datos en este punto son evidentes: el 66.1\% de las resoluciones adoptadas por el Consejo de Seguridad se han producido después de aquel 2 de agosto. ${ }^{3}$ Esto nos conduce a que en menos de la mitad de tiempo (en 21 años) se han adoptado el doble de resoluciones que las producidas entre $1945 \mathrm{y}$ el verano de 1990.

1 Véase la Resolución 660 (1990) del 2 de agosto, del Consejo de Seguridad que califica la acción de quebrantamiento de la paz.

2 En concreto, el profesor Dupuy lo califica como "sorte de surchauffe du système" en "Sécurité collective et organisation de la paix", RGDIP, 1993, p. 617, o en una expresión de F. Paolillo, el Consejo de Seguridad que hasta entonces era vegetariano, se ha transformado en carnívoro e iniciado el camino hacia la antropofagia, véase Paolillo, F., "Reclamaciones colectivas internacionales: el caso de los damnificados por la crisis del Golfo”, en varios autores, El derecho internacional en un mundo en transformación. Liber Amicorum Eduardo Jiménez de Aréchaga, Fundación de Cultura Universitaria, 1994, p. 545.

3 Al 18 de julio de 2011, la última de las resoluciones adoptadas por el Consejo de Seguridad es la 1999 (2011) sobre admisión de nuevos miembros, del 13 de julio. 
Es cierto que la extensión del listado puede parecer engañosa, como indica el profesor Remiro, en la medida en que algunos de los asuntos que en ella figuran como objeto de esas resoluciones "se mantienen ahí (en ese listado) por el empeño de quienes los propusieron de guardar su memoria; pero una veintena de temas han regado los debates y originado decisiones". ${ }^{4}$ Sin embargo, esto no es una novedad producida con posterioridad al verano de 1990, por lo que la multiplicación por tres del número de resoluciones, es clara muestra de lo que hemos calificado como hiperactividad cuantitativa en la acción del Consejo de Seguridad.

En el segundo de los sentidos antes indicado (cualitativo), debido a la originalidad de algunas de las medidas adoptadas, ${ }^{5}$ pues algunas resoluciones cuentan con contenidos novedosos desde 1990 si tenemos en cuenta la letra del Capítulo VII de la Carta, que ha sido interpretado de un modo más que extensivo. Pensemos en las resoluciones temáticas, por ejemplo, las referidas a las mujeres en la paz y la seguridad, ${ }^{6}$ los niños en los conflictos armados, ${ }^{7}$ la protección de civiles en los conflictos $\operatorname{armados}^{8}$ o la no proliferación de armas de destrucción en masa. ${ }^{9}$ El

\begin{abstract}
4 Véase Remiro Brotóns, A., "Carta de las NU-Nuevo Orden: ida y vuelta”, en varios autores, El derecho internacional: normas, hechos y valores. Liber Amicorum José Antonio Pastor Ridruejo, UCM, 2005, pp. 359 y ss., la cita del texto se encuentra en la página 369. Hay otras que no incorporan decisiones sustantivas ni adopción en sentido estricto de medidas, limitándose, como la 1969, del 24 de febrero, sobre Timor Oriental, a congratularse, alentar, subrayar, recordar, la única novedad que presenta es la prórroga del mandato de la UNMIT, creada con la resolución 1704 (2006, de 25 de agosto) para prestar apoyo al gobierno y a las instituciones pertinentes con miras a consolidar la estabilidad, fomentar la cultura de gobernanza democrática y facilitar el diálogo político entre las partes interesadas de Timor Leste en el proceso
\end{abstract} de reconciliación nacional y promoción de la cohesión.

Stromseth, J. E., "An Imperial Security Council? Implementing Security Council Resolutions 1373 and 1390. The Security Council's Counter-Terrorism Role: Continuity and Innovation”, American Society of International Law Proceedings, 2003, vol. 94, p. 42, se refiere a la "intensity of innovation" en la acción del Consejo de Seguridad producida en 1990 y los años siguientes; Hinojosa, L. M., "Las sanciones del Consejo de Seguridad contra Al-Qaeda y los talibanes ¿son realmente inteligentes”, REDI, vol. LVIII, 2006, 2, p. 738, habla de creatividad del Consejo de Seguridad en la interpretación de los poderes atribuidos por la Carta a este órgano.

6 Por ejemplo, la resolución 1325 (2000), 31 de octubre.

7 Por ejemplo, la resolución 1314 (2000), 11 de agosto.

8 Como la resolución 1373 (2001), del 28 de septiembre.

9 Es la resolución 1540 (2004), del 28 de abril. 
interés de los ámbitos materiales sobre los que versan estas resoluciones es indiscutible, no así que el fundamento de tales decisiones pueda ubicarse en el Capítulo VII de la Carta, pues no se trata de situaciones concretas que amenacen la paz y la seguridad internacionales, sino de categorías genéricas que no siempre lo hacen, y que en ocasiones son consecuencia de un conflicto previo, y en otras lo agravan. ${ }^{10}$

Podemos ubicar el punto de inflexión de la labor del Consejo de Seguridad en la reacción a la invasión y anexión de Kuwait por parte de Iraq, pues como consecuencia de las nuevas circunstancias mundiales, empezaría a adoptar decisiones que no resisten la comparación con las anteriores, debido a su originalidad característica de lo que hemos denominado efervescencia cualitativa, buena muestra de ello es la resolución 687 (1991).

A este despertar del Consejo de Seguridad contribuyeron significativamente dos factores: en primer lugar, la evolución de la sociedad internacional; en segundo término, el procedimiento de concertación previa de los miembros permanentes del Consejo de Seguridad. En cuanto al primero de ellos, es evidente que el final de la década de los ochenta y comienzos de los noventa supusieron un punto de inflexión en la sociedad internacional. La caída del Muro de Berlín y el desmembramiento de la Unión Soviética, con todas las consecuencias que de ambos fenómenos derivaron, tumbaron la realidad bipolar que hasta entonces había sido el fiel de la balanza del Consejo de Seguridad. La primera ocasión en la que tenemos oportunidad de ver los frutos de ese nuevo equilibrio es como consecuencia de la grave vulneración de una norma imperativa por parte de quien, durante la guerra del Golfo (irano-iraquí), había sido el aliado occidental. La invasión y anexión de Kuwait por parte de

10 No podemos olvidar en este punto las escandalosas resoluciones, auspiciadas por Estados Unidos durante la presidencia de G. W. Bush, aprobadas con el propósito de excluir la posible remisión a la Corte Penal Internacional a nacionales de Estados no partes en el Estatuto de Roma que participen en operaciones establecidas o autorizadas por UN. Véase la resolución 1422 (2002), del 12 de julio, sobre el mantenimiento de la paz por las NU (parágrafo 1) o la resolución 1497 (2003), del 1o. de agosto acerca de Liberia (parágrafo 7). Sin embargo, son resoluciones que formalmente se adoptan sobre la base que les proporciona el Estatuto de Roma, aunque materialmente discrepemos en este argumento, como veremos infra. Sobre las relaciones de Estados Unidos con la Corte Penal Internacional, véase Gutiérrez Baylón, J. de D., Sistema jurídico de las Naciones Unidas, México, Porrúa, 2007, pp. 147 y ss. 
Iraq consiguió despertar al Consejo del letargo, ${ }^{11}$ posibilidad con la que no contaba Sadam Hussein. ${ }^{12}$

El segundo efecto que contribuyó al despertar del Consejo de Seguridad fue la modificación del método de trabajo en su seno, que se había aplicado esporádicamente en $1987,{ }^{13}$ consistentes en una concertación informal entre sus miembros permanentes, lo que tiene ventajas e inconvenientes. La más importante de las ventajas se encuentra en la eficacia que imprime a su acción, ${ }^{14}$ ya que las reuniones de los miembros permanentes (el grupo denominado P-5), previas a las sesiones oficiales del Consejo de Seguridad, permiten aproximar posturas o limar asperezas acerca de los contenidos a incorporar en una resolución o detectar la imposibilidad de lograr un acuerdo, descartando la presentación de la resolución a consideración del Consejo.

Sin embargo, con todo lo anterior, dado que se trata de reuniones oficiosas, en ellas no se adoptan decisiones jurídicamente vinculantes para los participantes, se aleja (sin impedirlo) el siempre amenazante veto individual. Tampoco evita el ejercicio de veto colectivo, debido a la oposición un número suficiente de miembros no permanentes (7), pero cuya falta de organización favorece la aprobación de lo consensuado previamente entre el P-5. ${ }^{15}$

11 Lo que M. J. Aznar Gómez (en Responsabilidad internacional del Estado y acción del Consejo de Seguridad de las NU, Escuela Diplomática, 2000, p. 27) denomina letargo funcional relativo.

12 Véase Dupuy, P-M., "Les grands secteurs d'intérêt des organisations internationales", en Dupuy, R-J. (coord.), Manuel sur les Organisations internationales, 2a. ed., Martinus Nijjhof, 1998, p. 571.

${ }_{13}$ Véase Delon, F., "Le rôle joué par les membres permanents dans l'action du Conseil de Sécurité”, en Dupuy, R-J. (ed.), Le développement du rôle du Conseil de Sécurité, colloque la Haye 1992, Martinus Nijhoff, 1993, pp. 349 y ss.

14 Así, con ocasión de la invasión y anexión de Kuwait por parte de Iraq se adoptaron diez resoluciones en menos de dos meses (desde el 2 de agosto hasta el 25 de septiembre) en un único conflicto.

15 Sobre este particular véase Mahbubani, K., "The Permanent and Elected Council Members", en Malone, D. (ed.), The UN Security Council. From de ColdWar to the $21^{\text {st }}$ Century, Lynne Rienner Publishers, 2004, pp. 253 y ss.; también Fernández Rubio, E. M., "Sombras y luces en las dos dimensiones de la reforma del Consejo de Seguridad”, en Beneyto, J. M. y Becerril, B., Una nueva Organización de NU para el siglo XXI, Biblioteca Nueva-Instituto Universitario de Estudios Europeos de la Universidad CEU San Pablo, 2007, pp. 35 y ss., y "La otra cara de la reforma del Consejo de Seguridad. Sus métodos de trabajo", Anuario Mexicano de Derecho Internacional, vol. VIII, 2008, pp. 399 y ss. 
Entre los inconvenientes de la nueva dinámica, emerge con energía su opacidad, ya que, en palabras de Antonio Remiro, no son prácticas taxativamente contrarias al Reglamento provisional del Consejo

pero vacía de contenido principios fundamentales de la Carta y es, por lo menos, dudoso que el alegato de eficacia subyacente al escamoteo compense los costes en transparencia y participación en la toma de decisiones y el perjuicio que supone para la autoridad moral de las decisiones mismas. ${ }^{16}$

En todo caso, desde que se utiliza este nuevo método de reuniones previas a las sesiones del Consejo de Seguridad ha descendido el número de vetos ${ }^{17}$ y se ha multiplicado el de resoluciones adoptadas por el Consejo de Seguridad. La acción de este órgano principal ha ganado en eficacia pero perdido en transparencia.

Este es el contexto fáctico que me preocupa, en las páginas siguientes intentaré enfrentarme a dos retos claros: uno primero, identificar los problemas que, desde una perspectiva jurídica, suscitan algunas decisiones del Consejo de Seguridad (y algunos silencios), y uno segundo, indicar las potenciales soluciones que pueden resolver los anteriores; para terminar, como viene siendo habitual en estos casos, con unas conclusiones.

\section{LOS NUEVOS PROBLEMAS: LA ORIGINALIDAD DE LAS MEDIDAS ADOPTADAS POR EL CONSEJO DE SEGURIDAD Y LA FALTA DE CONTROL EN LA APLICACIÓN}

En los últimos veinte años, la concertación de los miembros permanentes del Consejo de Seguridad ha permitido la adopción de resoluciones de discutible acomodo en el Capítulo VII de la Carta, ya sea por la práctica

16 Véase al respecto, Remiro Brotóns, A., Civilizados, bárbaros y salvajes en el orden internacional, McGraw Hill, 1996, p. 203.

17 Sobre el derecho de veto véase Torres Cazorla, I., "El derecho de veto en el Consejo de Seguridad de NU: la historia de la válvula de seguridad que paralizó el sistema”, ACDI, Bogotá, 2008, pp. 49-88. 
calificadora desarrollada, ${ }^{18}$ considerada por M. Ortega como errática, absentista y exorbitante, ${ }^{19}$ cuando no manifiestamente falsa, o por su contenido novedoso. ${ }^{20}$ Todo ello nos permite caracterizar al Consejo de Seguridad por compaginar sus (in)acciones selectivas y sus acciones ultra vires. Además de lo anterior, se ha producido lo que la profesora Andrés ha denominado la "instrumentalización del Consejo por parte de algunos de sus miembros permanentes para adoptar sanciones en casos sumamente discutibles". ${ }^{21}$ En todo caso, en adelante focalizaremos nuestro interés en la creación de órganos subsidiarios por parte del Consejo de Seguridad en la adopción de resoluciones "legislativas", sin olvidar la justificación de la legalidad de las decisiones del Consejo de Seguridad, así como la ausencia de control en su aplicación.

\section{La creación de órganos subsidiarios}

Una de las características de estos nuevos tiempos ha sido la creación de órganos subsidiarios por el Consejo de Seguridad. En este punto, hemos de retrotraernos a principios del mes de abril de $1991 \mathrm{y}$, en concreto a la resolución 687, adoptada "de conformidad con el Capítulo VII de la Carta”, que marca el inicio de la originalidad creativa del Consejo de Seguridad. Entendemos la existencia de originalidad porque su contenido encuentra un acomodo discutible en aquel capítulo en el que han de

18 Sobre la interpretación del artículo 39 de la Carta, véase Serna Galván, M. de la, “Interpretation of Article 39 of the UN Charter (Threat of the Peace) by the Security Council. Is the Security Council a Legislator for the Entire International Community?", Anuario Mexicano de Derecho Internacional, vol. XI, 2011, pp. 147-185.

19 Véase Ortega Carcelén, M. C., Hacia un gobierno mundial, Salamanca, 1995, p. 113.

20 Falsedad ilustrada con la resolución 1530 (2004), del 11 de marzo de 2004, en la que se “Condena en los términos más enérgicos los atentados con bombas cometidos en Madrid (España) el 11 de marzo de 2004 por el grupo terrorista ETA ...”; adoptada cuando se conocía la autoría de grupos fundamentalistas de los actos terroristas objeto de condena.

21 Véase Sáenz de Santa María, P. Andrés, "Derecho, moral y eficacia en la práctica de sanciones del Consejo de Seguridad”, en Vargas, M. y Salinas, A. (coords.) Soberanía del Estado y derecho internacional: homenaje al profesor Juan Antonio Carrillo Salcedo, Servicio de Publicaciones de la Universidad de Sevilla, 2005,vol. 1, pp. 155-176, la cita se encuentra en la p. 156. 
encontrar fundamento formal y especialmente material los actos adoptados por este órgano en el marco del sistema de seguridad colectiva. ${ }^{22}$

El punto de partida ha de ser la competencia limitada del Consejo de Seguridad para crear órganos subsidiarios, pues así lo establece la Carta de las NU, en sus artículos 7.2 y $29 .{ }^{23}$ El primero de ellos, referido a la posibilidad de los órganos principales de la Organización de actuar de este modo. Por su parte, el artículo 29 (ubicado dentro de los poderes de este órgano) aplica específicamente aquel contenido al Consejo de Seguridad, facultándole al establecimiento de los órganos subsidiarios que considere necesarios "para el desempeño de sus funciones", en evidente referencia a aquéllas de las que es titular el órgano creador. Como ha establecido Santiago Torres, en su estudio sobre los órganos subsidiarios, ${ }^{24}$ su función es prestar asistencia a los órganos principales o a la propia organización internacional en cuya estructura se incardi-

22 Como indica Santiago Torres, las resoluciones del Consejo de Seguridad siempre "han evitado, más allá de toda justificación razonable, la mención de las disposiciones de la Carta en que se fundamentan, son poco sistemáticas en su presentación, no matizan lo suficiente los distintos aspectos que pueden presentar los comportamientos, controversias o situaciones considerados, amalgaman con frecuencia excesiva cuestiones relativas a distintos Capítulos de la Carta etc." (véase S. Torres, "Perspectivas en la contribución de las NU al mantenimiento de la paz y seguridad internacionales: comentarios y observaciones sobre la declaración de los miembros del Consejo de Seguridad de 31 de enero de 1992”, en Pérez González, M. (coord.), Hacia un nuevo orden internacional y europeo: estudios en homenaje al profesor don Manuel Díez de Velasco, Madrid, 1993, pp. 727 y ss. La transcripción del texto se encuentra en la p. 757). Cualquiera de estas imprecisiones o ausencias, individualmente consideradas, motivarían la nulidad de los actos decididos si fueran adoptadas en el seno de otras Organizaciones Internacionales. Véase en este sentido el recurso de anulación en el caso de la Unión Europea (artículo 263 del Tratado de Funcionamiento) y observaremos que en la relación apuntada por S. Torres aparece más de un vicio sustancial de forma (falta de motivación, motivación insuficiente, errónea determinación de la base jurídica...) o incluso por desviación de poder.

23 Véanse comentarios a los artículos 7 y 29 de la Carta realizados respectivamente por T. Melescanu y E. Decaux , publicados en J-P. Cot, A. Pellet y M. Forteau, La Charte des Nations Unies. Commentaire article par article, 3a. ed., Económica, vol. I, 2005, pp. 575, 975 y ss.

${ }^{24}$ Véase Torres Bernárdez, S., "Subsidiary Organs”, en Dupuy, P. M. (dir.), Manuel sur les Organisations Internationales, Martinus Nijhoff, 1988, pp. 100 y ss., la afirmaciones del texto se encuentran respectivamente en las páginas 106 (la inexistencia de reglas generales) y 119 . En la segunda edición de la obra las afirmaciones se mantienen en las páginas 110 y 126 . En el mismo sentido véase entre otros, Condorelli, L., "Le Tribunal Penal International pour l'exYougoslavie et sa jurisprudence", Cursos Bancaja de Derecho Internacional, 1997, vol. I, pp. 245 y ss., especialmente pp. 261 y ss. 
na. De acuerdo con lo anterior, el alcance de las funciones delegadas a un órgano subsidiario es limitado y siempre ha de responder al ámbito competencial del principal que lo ha creado, ${ }^{25}$ sentido en el que ya se había formulado la Corte Internacional de Justicia (en adelante CIJ). ${ }^{26}$

Con estos mimbres, el Consejo de Seguridad, a través de su resolución 687, establece (e impone) órganos subsidiarios a los que confiere competencias de las que carece el órgano creador: la Comisión de demarcación de fronteras y la de indemnizaciones o de compensación, ${ }^{27}$ que parecen incorrectamente ubicadas en el Capítulo VII de la Carta. En el primer caso, porque el objeto del órgano era resolver la controversia fronteriza existente entre Iraq y Kuwait; mientras en el segundo, el propósito perseguido era la aplicación de un régimen de responsabilidad a Iraq y sus consecuencias reparadoras, es decir, la indemnización por los daños producidos a particulares y empresas como consecuencia de la anexión de Kuwait y sus desarrollos posteriores. Materialmente, ambas acciones resultan de más fácil acomodo en el Capítulo VI, dedicado a la solución pacífica de diferencias internacionales.

25 En el mismo sentido véase Mosler, H., "La organización internacional y la distribución de competencias", Escuela de Funcionarios Internacionales, Cursos y Conferencias del curso 1955-56, Madrid 1957, vol. I, p. 577; Reuter, P., "Les organismes subsidiaires des organisations internationales", Hommage d'une génération de juristes au Président Basdevant, Pedone, 1960, p. 426, Colliard, C-A., Institutions des relations internationales, 7a. ed., Dalloz, 1978, p. 657, o Torres Bernárdez, S., cit., p. 141, y en la p. 149 de la 2a. ed. (1998).

26 La CIJ en la Opinión Consultiva, de 13 de julio de 1954, sobre el efecto de las sentencias del Tribunal Administrativo de NU, afirmó la capacidad jurídica de la Asamblea General para crear el tribunal administrativo cuestionándose sobre el efecto de cuyas sentencias se cuestionaba al Tribunal (Véase CIJ, Rec. des C., 1954, p. 61).

27 Véase Townsend, G., "The Iraq Claims Process: A Progress Report on the United Nations Compensation Commission \& U.S. Remedies", Loy. L.A. Int'1 \& Comp. L.J., 1994-1995, vol. 17, pp. 973 y ss.; Lillich, R., The United Nations Compensation Commission:Thirteenth Sokol Colloquium, Hotei Publishing, 1995; Frigesi di Rattalma, M., The United Nations Compensation Commission, Kluwer, 1999; Heiskanen, V., "The United Nations Compensation Commission”, Rec. des C., 1996, vol. 296, pp. 255 y ss.; Affaki,B. G., "The United Nations Compensation Commission: A New Era in Claims Sttlements?”, Journal of International Arbitration, 1997, núm. 3, pp. 21 y ss.; Lillich, R. y Brower, Ch. N. "Opinion Regarding the Jurisdiction and Powers of the United Nations Compensation Commission (February 10, 1992)”, Va. J. Int'l L., 1997-1998, vol. 38, p. 25 y ss.; Torrecuadrada, S., "Los límites a los poderes del Consejo de Seguridad. La Comisión de compensación de NU”, Cursos de Derecho Internacional y Relaciones Internacionales deVitoria-Gasteiz, 2009, Universidad del País Vasco, 2010, pp. 225 y ss. 
Es claro que, sobre las competencias que posee el Consejo de Seguridad, actuando sobre el Capítulo VI deberían respetarse las bases del principio en él contenido, entre ellas la libre elección de medios y el carácter recomendatorio de sus decisiones que no pueden imponerse por vía de autoridad, a diferencia de lo que sucede en aplicación del Capítulo VII. Las dos comisiones realizaron la labor encomendada procediendo a la indicación de reparaciones sin mediar acuerdo de las partes, por la ausencia impuesta de Iraq, principalmente afectado. Con sus decisiones se modificaron permanentemente los derechos territoriales de las partes en el caso de la delimitación fronteriza y los económicos de Iraq, en el de la comisión de indemnizaciones. Este efecto difícilmente puede lograrse utilizando como fundamento el Capítulo VII de la Carta, de cuya interpretación se desprende que las medidas adoptadas han de presionar al Estado que amenaza o quebranta la paz o realiza un acto de agresión, a que reconduzca su actitud sin alterar definitivamente los derechos de las partes en conflicto, que es precisamente el efecto del trabajo de los órganos subsidiarios que consideramos.

Por otro lado, no podemos olvidar que el Consejo de Seguridad es un órgano político y la imposición de la solución de una controversia territorial entre dos Estados es propia de un órgano jurisdiccional (ya sea judicial o arbitral). En este caso, el Consejo hizo suyas las decisiones adoptadas por la Comisión, motivo por el cual, se impusieron como jurídicamente obligatorias debido a la autoridad del órgano emisor cuando actúa sobre el Capítulo VII de la Carta que, no olvidemos, son fuente de obligaciones para los Estados miembros (en virtud de la interpretación conjunta de los artículos 25 y 103 de la Carta, ${ }^{28}$ avalada por la CIJ en su jurisprudencia que ha establecido la prevalencia de las decisiones del Consejo adoptadas en aplicación del Capítulo VII de la Carta sobre cualesquiera otras), ${ }^{29}$ lo que no ocurre cuando actúa con fundamento en

28 Véase Gutiérrez Baylón, J. de D., Sistema..., cit.

29 La Corte en su jurisprudencia ha reiterado la interpretación conjunta de ambos preceptos, véase la Sentencia del 26 de noviembre de 1984 en el asunto de Las actividades militares y paramilitares en y contra Nicaragua (excepciones preliminares, CIJ, Recueil 1984, p. 440, parágrafo 107) o en la Ordenanza de 14 de abril de 1992, en la que se pronuncia sobre las medidas cautelares en las Cuestiones de interpretación y aplicación de la Convención de Montreal d 1971 como consecuencia del incidente aéreo de Lockerbie (Jamahiriya arabe libyenne c. Reino Unido), (en C.I.J. Recueil 1992, p. 15, par. 39), contenido reproducido en la Ordenanza de la misma fecha en 
el capítulo precedente, contexto en el que sus decisiones son meramente recomendatorias.

Además de lo anterior, el Consejo de Seguridad, identificó el instrumento aplicable en la operación demarcadora (las "Minutas convenidas entre el Estado de Kuwait y la República del Iraq sobre el restablecimiento de las relaciones de amistad, el reconocimiento y asuntos Conexos", firmadas por ambos en Bagdad, el 4 de octubre de 1963), pese a su rechazo histórico por parte de Iraq. ${ }^{30}$ El Consejo de Seguridad entra a considerar como tratado internacional un instrumento sobre cuya naturaleza (jurídica o política) existía una diferencia entre las partes, resuelta unilateralmente por el órgano principal, en el marco del Capítulo VII de la Carta, lo que claramente excede a las competencias que este fundamento le proporciona.

Si bien ambas comisiones son órganos subsidiarios del Consejo de Seguridad, la labor encomendada a la Comisión de conciliación o indemnizaciones es la de mayor complejidad al dotársele de pluralidad funcional, ya que se encarga de recibir las reclamaciones, decidir acerca de su procedencia y asignarle, en su caso, la cuantía correspondiente, además de administrar el Fondo de Indemnización de las NU, nutrido de un porcentaje aplicado sobre las exportaciones iraquíes de petróleo

el mismo asunto entre Libia y Estados Unidos, parágrafo 42, pp. 126. El juez Rezek en su opinión individual a la sentencia del 27 de febrero de 1998, en el asunto de Lockerbie (véase. sentencia de Libia c. Reino Unido en p. 61 y en la sentencia Libia c. Estados Unidos p. 153) rechaza la conclusión apuntada en el texto, al considerar que el artículo 103 de la Carta es una regla de solución de conflictos entre tratados a favor de la Carta, con independencia de criterios de especialidad o posterioridad, a los que beneficia la regla general contenida en el artículo 30 de la Convención de Viena de 1969 a estos efectos (excluyendo expresamente de su aplicación lo establecido en el artículo 103 precitado); pero no al derecho secundario de la Organización, categoría en la que se encuentran las resoluciones del Consejo de Seguridad. Sin embargo, hemos de entender que esa obligatoriedad reforzada de las resoluciones del Consejo de Seguridad existe siempre que estos actos sean acordes con la Carta (tanto desde una perspectiva formal como material, lo que López-Jacoiste, E., Actualidad del Consejo de Seguridad de las NU, Thomson-Civitas, 2003, p. 55, denomina imperatividad de las resoluciones del Consejo de Seguridad), pero no cuando excedan los límites derivados de ella en cuyo caso no puede gozar de ese beneficio por el exceso producido.

30 Sobre esta cuestión puede verse, entre otros, Mendelson, M. H. y Hulton, S. C., "La revendication par l'Irak de la souveraineté sur le Kuwait”, AFDI, 1990, pp. 195 y ss. 
y liquidar el importe de lo decidido. ${ }^{31}$ Todo ello sin que las reglas de procedimiento ante la Comisión concedieran a Iraq un papel distinto al de cualquier otro Estado que hubiera presentado reclamaciones. ${ }^{32}$

No está de más recordar que el Consejo de Seguridad puede activar el Sistema de Seguridad Colectiva exclusivamente en presencia de una amenaza para la paz, un quebrantamiento de la paz o un acto de agresión, ${ }^{33}$ y, en la fecha en la que se aprueba la resolución 687, Kuwait se había liberado de la anexión iraquí; por lo que la ilicitud iraquí ya había desaparecido. ${ }^{34}$ Aun obviando este hecho, ${ }^{35}$ la creación de ambas comisiones no se acomoda fácilmente al modelo de medidas que pueden adoptarse en aplicación de este Capítulo VII (y, en concreto, en los artículos 40 a 42 de la Carta) que perfila el ámbito competencial atribuido al Consejo de Seguridad. De ellos, sólo el artículo $41^{36}$ pudiera amparar la decisión creadora, aunque una interpretación de su contenido contextualizado en el Sistema de Seguridad Colectiva y en general en la Carta (de acuer-

31 De las mismas exportaciones de petróleo que se financia también el programa petróleo por alimentos. Sobre los problemas que suscitó la aplicación de este programa véase Méndez Silva, R., "La globalización corrompe globalmente: el programa petróleo por alimentos para Iraq”, en Méndez Silva, R. (coord.), Lo que todos sabemos sobre la corrupción y algo más, México, UNAM, Instituto de Investigaciones Jurídicas, 2010, pp. 103 y ss.

32 Algunos autores, como A. Gattini, justificaban limitada intervención iraquí en el procedimiento en el propósito de que este Estado tuviera «cognizance of the claims submitted and to cooperate with the panels of commissioners» (V'éase en "The United Nations Compensation Commission: Old Rules, New Procedures on War Reparations”, EJIL, 2002, pp. 161 y ss. la cita es de la p. 168).

33 Véase Serna Galván, M. de la, "Interpretation of Article 39...", op. cit.

34 Recordemos en este punto a H. Kelsen (The Law of the United Nations, Stevens and Sons, 1951, pp. 735 y ss.).

35 El Consejo de Seguridad en la resolución 687 justifica torpemente su aprobación, sólo afirma "la necesidad de adoptar las medidas siguientes de conformidad con el Capítulo VII de la Carta" y "teniendo presente su objetivo de restablecer la paz y la seguridad internacionales en la región de conformidad con sus resoluciones recientes”. Se felicita por la recuperación de la soberanía kuwaití, y reitera "la necesidad de tener seguridades de que las intenciones del Iraq son pacíficas, habida cuenta de que ese país invadió y ocupó ilegalmente Kuwait...” se muestra "consciente de la necesidad de demarcar esa frontera...".

36 No son medidas con fundamento en el artículo 40 de la Carta, véase, en este sentido el Comentario de Sorel, J. M., en Cot, J-P. et al., La Charte des Nations Unies. Commentaire article par article, 3a. ed., Económica, 2005, pp. 1171 y ss., tampoco pueden ubicarse en el artículo 42, véase el Comentario de P. Daillier, en la misma obra, pp. 1243 y ss. El comentario sobre el artículo 41 está firmado por E. Lagrange y P-M. Eisemann, y se encuentra en pp.1195 y ss. 
do con la regla general para la interpretación de los tratados establecida en el artículo 31 de la Convención de Viena de 1969), nos conduce a dudar de su validez como fundamento válido.

Por último, debido a que son de más reciente aparición que las comisiones referidas, los tribunales penales para la antigua Yugoslavia ${ }^{37}$ y para Ruanda $^{38}$ son igual que aquellos órganos subsidiarios con funciones judiciales. En este sentido podemos apuntar las dudas indicadas antes, junto con las planteadas por F. L. Kirgis, ${ }^{39}$ sobre la legitimidad de la creación de la Comisión de compensación y las formuladas en relación con los tribunales penales internacionales para Yugoslavia y para Ruanda.

Las dudas sobre el alcance competencial del Consejo de Seguridad para crear estos tribunales se presentaron en forma de excepción preliminar de incompetencia ante el primero de ellos (el Tribunal para la antigua Yugoslavia), fundada precisamente sobre la actuación ultra vires de este órgano. La sala de apelaciones arguyó entonces que el Consejo de Seguridad goza de un amplio poder discrecional para decidir las medidas a adoptar en cada caso concreto "a prendre et evaluer leur

37 Sobre este punto véase Weckel, Ph., "L'institution d'un Tribunal International pour la répression de droit humanitaire en Yougoslavie”, AFDI, 1993, p. 232 y ss.; Lescure, K., Le Tribunal Penal International pour l'exYougoslavie, París, 1994, especialmente pp. 81 y ss; Huesa Vinaixa, R., "El Tribunal Internacional para juzgar los crímenes cometidos en la ex Yugoslavia y la sanción internacional de los crímenes contra la paz y la seguridad de la humanidad”, Cursos de Derecho Internacional y Relaciones Internacionales deVitoria-Gasteiz, 1994, pp. 155 y ss.; Condorelli, L., "Le Tribunal Penal International pour l'ex Yougoslavie et sa jurisprudence”, Cursos Bancaja de Derecho Internacional, 1997, vol. I, pp. 245 y ss.; Pigrau, A. "Elementos del derecho internacional penal", Cursos de Derecho Internacional y Relaciones Internacionales deVitoria-Gasteiz, 1997, pp. 133 y ss.; Aksar, Yusuf, Implementing International Humanitarian Law: from the ad hoc tribunals to a permanent international Criminal Court, Londres-Nueva York, Routledge, 2004; Comellas Aguirrezábal, M. T., La incidencia de la práctica del Consejo de Seguridad en el derecho internacional humanitario, Pamplona, Thomson-Aranzadi, 2007, p. 304.

38 Sobre el Tribunal Penal Internacional para la antigua Yugoslavia véanse las resoluciones 808, del 22 de febrero y 827, del 25 de mayo, y la resolución 955 (1994) del 8 de noviembre sobre el establecimiento de un Tribunal Penal internacional para Ruanda y la aprobación de su estatuto.

39 Véase Kirgis, F. L., "Claims Settlement and the UN Legal Structure”, en Lillich, R. B., The United Nations Compensation Commission, Transnational Publishers, 1995, pp. 103 y ss., especialmente p. 110. 
caractère adéquat", ${ }^{40}$ en una argumentación ligera e interesada de las competencias del Consejo de Seguridad. Ligera, pues el Tribunal para la antigua Yugoslavia carece de competencias de interpretación de la Carta y de las que este texto le atribuye a uno de sus órganos principales. Interesada, dado que aquél sobre cuya competencia se está pronunciando es precisamente su órgano creador y, la decisión en un sentido diferente al que lo hizo, habría supuesto la desaparición del Tribunal en cuestión.

En todo caso, a pesar de las dudas que sobre el correcto fundamento en el sistema de seguridad colectiva surjan, es justo reconocer que la creación de ambos tribunales ha sido la mayor aportación del Consejo de Seguridad al derecho humanitario.

\section{Las resoluciones "legislativas"}

Calificamos como "legislativas" las resoluciones en las que el Consejo de Seguridad actúa como si de un órgano titular de poderes de este carácter se tratara, al imponer modelos de conducta obligatorios y generales. Fue a partir del 11 de septiembre de 2001 cuando el Consejo de Seguridad comienza a producir resoluciones en materia de terrorismo con una clara vocación de creación de normas generales. ${ }^{41}$

Hay resoluciones anteriores a esta fecha en materia de terrorismo pero, a diferencia de las que se producen después, se refieren a ataques

40 Es el parágrafo 31 de la Sentencia del 2 de octubre de 1995 de la Sala de Apelaciones del TPIY, en el asunto de Dusko Tadic (IT-94-1-AR 72). La amplísima extensión de los poderes discrecionales del Consejo de Seguridad se reitera en el parágrafo 39 de la misma sentencia.

${ }^{41}$ Ciertamente, antes de esta fecha ya había calificado este fenómeno como una amenaza para la paz y la seguridad internacionales (res. 1269, de 1999). Incluso, años antes (en enero de 1992), los jefes de Estado y de Gobierno de los Estados miembros del Consejo de Seguridad expresaron "su profunda preocupación por los actos de terrorismo internacional y destacan la necesidad de que la Comunidad internacional haga frente a todos esos actos de manera efectiva”. Es en la Declaración del 31 de enero de 1992. Adviértase que ese texto se refiere a "todos" los actos de terrorismo internacional (voluntad de generalidad) y no a un conflicto o situación concreta (presupuesto de aplicación del Capítulo VII de la Carta). Esta referencia provocó que S. Torres afirmara que “de un tiempo a esta parte, el Consejo de Seguridad, parece decidido a tomar en sus manos la lucha contra el 'terrorismo internacional"”. Véase Torres, S., "Perspectivas en la contribución de las UN...”, op. cit., p. 749. 
o a amenazas terroristas concretas. ${ }^{42}$ La primera de ellas es la resolución 1373 (2001) que, bajo la rúbrica de: "La amenaza para la paz y la seguridad internacionales creadas por actos de terrorismo", califica todos los actos de terrorismo internacional como una amenaza para la paz y la seguridad internacionales; ${ }^{43}$ se dirige a una categoría generalmente definida: no impone comportamientos a un Estado particular ni a una parte en un conflicto, sino a todos ellos, pues les obliga a implicarse activamente en la lucha contra la financiación del terrorismo.

A diferencia de otras ocasiones en las que invita a los Estados a adherirse al Convenio Internacional para la Represión de la Financiación del Terrorismo, ahora compele por vía de autoridad algunos de sus contenidos. ${ }^{44}$ Así, establece la obligación de todos los Estados de prevenir activamente el terrorismo, que deberán modificar la ley penal para tipificar "como delito la provisión o recaudación intencionales, por cualesquiera medios, directa o indirectamente, de fondos por sus nacionales o en su territorio con la intención de que dichos fondos se utilicen, o con conocimiento de que dichos fondos se utilizarán, para perpetrar actos de terrorismo" (contenido coincidente con el del artículo 4.a del Convenio), además de adoptar las medidas necesarias para congelar de forma inmediata sus vías de financiación, ya sean directas como indirectas. ${ }^{45}$

42 Recordemos en este sentido la resolución 286 (1970), sobre los actos que ponen en peligro la aviación civil; la resolución 579 (1985), sobre el secuestro y la toma de rehenes; la resolución 635 (1989) relativa al uso de explosivos plásticos con fines terroristas; la resolución 638 (1989), de nuevo sobre la toma de rehenes y el secuestro; la resolución 748 (1992), adoptada a propuesta de los Estados Unidos, el Reino Unidos y Francia, la imposición de sanciones a Libia se justifica inter alia, en la determinación que hace el Consejo de Seguridad de que el Gobierno libio no ha "renunciado al terrorismo"; la resolución 1269 (1999) sobre la adopción de medidas destinadas a erradicar el terrorismo internacional; y la resolución 1368 (2001) de 12 de septiembre, sobre las amenazas para la paz y la seguridad internacionales creadas por actos de terrorismo.

${ }^{43}$ En la resolución 1373 (2001) el Consejo de Seguridad se refiere a una situación abstracta e impersonal, no a Afganistán, situación particular en relación a la que el Consejo actuaba paralelamente, adoptando durante ese periodo la resolución 1378 (2001), de 14 de noviembre, la resolución 1383 (2001), del 6 de diciembre o la resolución 1386 (2001), de 20 de diciembre que sí versaban monográficamente sobre la situación en aquel Estado asiático.

${ }^{44}$ Véase Remiro Brotóns, A., “Terrorismo internacional, principios agitados”, en Jiménez, F. y Cuerda, A. (dirs.), Nuevos desafíos del derecho penal internacional. Terrorismo, crímenes internacionales y derechos fundamentales, Madrid, Tecnos, 2009, p. 33.

45 También han de abstenerse los Estados de ayudar a estos grupos, debiendo adoptar (según lo establecido en el parágrafo 2 de la resolución 1373) cuantas medidas consideren 
Es claro que aquella primera resolución (la 1373) afecta de modo directo al ejercicio de la soberanía territorial del Estado que, de acuerdo con el laudo arbitral de la Isla de Palmas supone el derecho en exclusiva “de ejercer las actividades estatales". ${ }^{46}$ Además, en ella decide crear un nuevo órgano subsidiario, en esta ocasión "para que verifique la aplicación de la presente resolución, con la asistencia de los expertos que se consideren apropiados". ${ }^{47}$

Estas medidas son jurídicamente obligatorias para los miembros de NU, no sólo porque así se desprenda de sus términos (pues no invita, ni llama la atención, sino que el Consejo decide), sino también por el efecto de las resoluciones del Consejo, fruto de la interpretación conjunta de los artículos 25 y 103 de la Carta. Por otra parte, la utilización del verbo decidir, lejos de ser casual, se aproxima a la redacción del artículo 39 de la Carta que nos indica que tras la calificación de la situación, el Consejo "hará recomendaciones o decidirá qué medidas serán tomadas...".

Por si tuviéramos dudas sobre la obligatoriedad apuntada, como indica C. Denis, la práctica posterior del Consejo avala esta interpretación. ${ }^{48}$ Así, la resolución 1377 (2001) "pone de relieve la obligación de los Estados de denegar asistencia financiera y todas las demás formas de apoyo y

necesarias (también legislativas) para prevenir y reprimir los actos terroristas (lo que dice también el artículo 4.b del Convenio), ejercer su jurisdicción sólo sobre los presuntos terroristas y sobre quienes les presten cualquier tipo de ayuda (identidad con los artículos 7o. y 8o. del Convenio); estando igualmente obligados a denegarles “cobijo", impidiendo su circulación por el territorio nacional; además de profundizar en la cooperación internacional en lo que a investigación y procedimientos penales relacionados en la resolución se refieren (igual que los artículos 9o. y 12 del Convenio).

46 Véase en Cour Permanente d'arbitrage, Ile de Palmas, sentencia arbitral de Max Huber, 4 de abril de 1928, R.S.A., vol. II, p. 839.

47 La estructura de este Comité reproduce la de la Comisión de compensación antes vista, ya que su órgano decisor va a ser un alter ego del Consejo de Seguridad, que controla sus actividades, al estar compuesto por representantes de sus miembros. Véase Kirgis, F. L. jr , "Claims Settlement and the United Nations Legal Structure", en Lillich, R. B., United Nations Compensation Commission, Transnational Publishers, 1995, pp. 103 y ss., especialmente pp. 108 y ss., también Heiskanen, V., "United Nations Compensation Commission”, Rec.des C., 2002, p. 271.

48 Véase Denis, C., Le pouvoir normatif du Conseil de Sécurité des Nations Unies: portée et limites, Bruylant, 2004, p. 147. 
de cobijo a los terroristas y a los que apoyan el terrorismo", en referencia a la precedente que considera fuente de esa obligación. ${ }^{49}$

La resolución 1540 (2004), sobre la no proliferación de armas de destrucción masiva, es otro ejemplo de la flexibilidad del Consejo en la que retoma la inspiración y el modelo de la resolución 1373 (2001), expresamente relacionada con esta última; ${ }^{50}$ ya que la reconoce como precedente. Actuando de nuevo sobre el Capítulo VII de la Carta, la resolución 1540 impone a los Estados la obligación de “abstenerse de suministrar cualquier tipo de apoyo a los agentes no estatales que traten de desarrollar, adquirir, fabricar, poseer, transportar, transferir o emplear armas nucleares, químicas o biológicas y sus sistemas vectores”, presumiéndose terroristas estos comportamientos en relación con esos agentes no estatales. ${ }^{51}$

Un año más tarde el Consejo de Seguridad adopta la resolución 1624 (2005), en la que, siguiendo los modelos anteriores, inicia la vía para la persecución de la apología del terrorismo, pues es "amenaza para el desarrollo social y económico de todos los Estados, socava la estabilidad y

49 Otras resoluciones posteriores son más claras al reiterar la obligatoriedad, la resolución 1390(2002), es meridiana al recordar sin tapujos "la obligación impuesta a todos los Estados Miembros de aplicar en su totalidad la resolución 1373 (2001)”; o, la resolución 1438 (2002) en la que se condenan los ataques con bombas en Bali "Insta a todos los Estados a que, de conformidad con las obligaciones que les competen en virtud de la resolución 1373 (2001)...”.

50 En la resolución 1540 (2004) el Consejo de Seguridad se reconoce "Sumamente preocupado por la amenaza del terrorismo y el riesgo de que agentes no estatales como los identificados en la lista de las NU elaborada y mantenida por el Comité establecido en virtud de la resolución 1267 (1999) del Consejo de Seguridad y aquéllos a los que se aplica la resolución 1373 (2001) puedan adquirir, desarrollar o emplear armas nucleares, químicas y biológicas y sus sistemas vectores o traficar con ellas".

51 Entendiendo por tales a la "persona física o entidad que no actúa bajo la autoridad legítima de un Estado en la ejecución de actividades comprendidas en el ámbito de las presente resolución”. El Consejo decide también que los Estados miembros “deben adoptar y aplicar leyes apropiadas y eficaces que prohíban a todos los agentes no estatales la fabricación, la adquisición, la posesión, el desarrollo, el transporte, la transferencia o el empleo de armas nucleares, químicas o biológicas y sus sistemas vectores, en particular con fines de terrorismo"; alcanzando la prohibición no sólo a la autoría, sino también a la tentativa o la complicidad, tanto directa como indirecta (para "prestarles asistencia o financiarlas"). Las que figuran en el texto se añaden otras obligaciones concretas en materia de prevención y represión de los comportamientos prohibidos que nos recuerdan en gran medida al contenido de la resolución 1373 (2001) y que no reproducimos aquí por razones de espacio. Véase, por ejemplo, el parágrafo tercero de la resolución 1549 (2004). 
prosperidad mundiales... y subrayando la necesidad de adoptar todas las medidas necesarias y apropiadas de conformidad con el derecho internacional, en los planos nacional e internacional...”. ${ }^{52}$ En esta resolución, se imponen nuevamente obligaciones generales a los Estados con una incidencia directa en su capacidad legislativa.

\section{Justificación de la originalidad del Consejo de Seguridad}

Frente a las críticas a las acciones del Consejo de Seguridad por esta interpretación manifiestamente extensiva de las competencias que le atribuye la Carta, ${ }^{53}$ nos encontramos con quienes pretenden justificarlas con diversos argumentos, entre los que destacan los siguientes: (1) la eficacia; (2) la naturaleza política del órgano; (3) la modificación de la Carta como consecuencia de la costumbre internacional.

52 Para medidas concretas, véase la resolución 1624 (2005).

53 En los últimos años han proliferado los estudios cuestionándose sus poderes y la interpretación excesivamente extensiva de los mismos han conducido a su extralimitación. Sólo a partir de 2000 destacan las monografías de Denis, C., Le pouvoir normatif du Conseil de Sécurité des Nations Unies: Portée et limites, Bruylant, 2004 ; E. de Wet, The Chapter VII Powers of the United Nations Security Council, Hart Publishing, 2004; Thomé, N., Les pouvoirs du Conseil de Sécurité au regard de la pratique récente du Chapitre VII de la Charte des Nations Unies, Presses Universitarires d'Aix-Marseille, 2005. Véase también en relación con las cuestiones actuales sobre el Consejo de Seguridad, la Revue Belge de Droit International, 2004-2, pp. 458 y ss. En la doctrina española se han producido múltiples estudios entre ellos: San José, A., "Las consecuencias jurídicas de los actos ultra vires de las organizaciones internacionales, en particular la ONU”, REDI, vol. XLII, 1990, 2, pp. 443 y ss., Abellán, V., "La ampliación del concepto de 'mantenimiento de la paz y seguridad internacional' por el Consejo de Seguridad de las NU: fundamento jurídico y discrecionalidad”, en Pérez González, M. (coord.), Hacia un nuevo orden internacional y europeo estudios en homenaje al profesor don Manuel Díez de Velasco, Tecnos, 1993, pp. 3 y ss.; Casado, R., "Consideraciones sobre el control de las decisiones del Consejo de Seguridad de NU”, ADI, 1994, pp. 335 y ss.; Fernández Casadevante, C., "El poder y el derecho en las NU: la discrecionalidad del Consejo de Seguridad”, en Fernández de Casadevante, C. y Quel, J. (coord.), Las NU y el derecho internacional, Ariel, 1997, pp. 40 y ss.; Pastor, J. A., “¿Nuevo gendarme de la paz y la seguridad internacionales? A propósito de la Guerra de Irak de la primavera de 2003”, Pacis Artes obra homenaje al profesor Julio D. González Campos, Editer, 2005, v. I, pp. 463 y ss.; López-Jacoiste, M. E., Actualidad del Consejo de Seguridad de las $N U$, Thomson-Civitas, 2003, junto a una amplia producción sectorial que no reproduciremos aquí por su extensión. 
En cuanto a la primera, la eficacia no es un argumento jurídico suficiente para permitir un exceso en el ejercicio de las competencias atribuidas por el texto constitutivo de la Organización de la que el Consejo de Seguridad es uno de sus órganos principales. En todo caso, la eficacia no es nunca ni puede ser una justificación jurídicamente sostenible cuando para alcanzarla se deja de respetar la legalidad.

En relación con la segunda, la naturaleza política del órgano, el profesor Sur afirma que el Consejo de Seguridad es un órgano político y su derecho ni está realizado por juristas ni dirigido a ellos. ${ }^{54} \mathrm{~A}$ pesar de lo anterior, lo cierto es que las competencias del órgano derivan de un tratado internacional, instrumento de naturaleza jurídica que ha de interpretarse con los métodos interpretativos establecidos en la Convención de Viena sobre el Derecho de los Tratados. En apoyo de esta afirmación encontramos la opinión consultiva de la CIJ, sobre las condiciones de admisión de un Estado como miembro de las NU, en la que la Corte afirmaba que el carácter político de un órgano no puede sustraerse a las disposiciones convencionales que lo rigen, especialmente si actúan como límite de sus competencias. ${ }^{55}$ Por tanto, con independencia de la naturaleza del órgano, si está regido por un texto jurídico habrá de someterse a él.

En cuanto a la existencia de una costumbre modificativa de la letra de la Carta, se pone como ejemplo el ejercicio del derecho de veto contemplado en el artículo 27 que prevé la necesidad de voto afirmativo de los cinco miembros permanentes para que prospere una resolución del Consejo de Seguridad, que evolucionó hasta entender que el veto se ejerce votando negativamente y no de otro modo, por lo que para que prospere una decisión será suficiente la ausencia de oposición de los miembros permanentes. ${ }^{56}$ En este punto considero que una cosa es

54 Véase Sur, G., "La resolution 687 (3 avril 1991) du Conseil de Sécurité dans l'affaore du Golfe: Problèmes de rétablissement et de garantie de la paix", Annuaire Français de droit international, 1991, pp. 17 y ss.

55 Opinión Consultiva del 28 de mayo de 1948, en CIJ, Recueil 1948, pp. 57 y ss. Puede consultarse en http://www3.icj-cij.org/docket/files/3/1820.pdf.

56 La CIJ se pronunció en este sentido en la Opinión Consultiva de 21 de junio de 1971, sobre las consecuencias jurídicas derivadas de la presencia continuada de Sudáfrica en Namibia, en cuyo parágrafo 22 establece: "L'abstention d'un membre du Conseil ne signifie pas qu'il s'oppose à l'approbation de ce qui est proposé; pour empêcher l'adoption d'une réso- 
la modificación del procedimiento de adopción de decisiones por las dinámicas del órgano en cuestión y otra una alteración tan sustantiva como la que se plantea, en la que no puede valernos la opinión y comportamiento de los cinco miembros permanentes o los quince si queremos implicar a todos los miembros del Consejo de Seguridad, sino que deberíamos escuchar también al resto de los miembros de NU que son muchos más (algo más de un 93.1\%) y elevan voces discrepantes.

Junto a ellos, hay quienes afirman la inexistencia de límites a los poderes del Consejo, afirmando su capacidad para aplicar el Sistema de Seguridad Colectiva aun en ausencia de las categorías previstas en el artículo 39, y sin que precise para desencadenar aquel sistema calificación alguna. ${ }^{57}$ Sin embargo, los límites existen y vienen determinados por la atribución competencial y por los propósitos y principios de la organización.

\section{La falta de control en la aplicación de las decisiones del Consejo de Seguridad}

La falta de control en la aplicación de las decisiones del Consejo de Seguridad no es un problema nuevo. Nunca han existido estos mecanismos y no hemos tenido más órganos subsidiarios que ahora. Es cierto que, en los últimos tiempos, algunas resoluciones incorporan la creación de órganos de control $^{58}$ que tienen un alcance concreto y no alcanza a la generalidad de las decisiones adoptadas por el Consejo de Seguridad.

En consecuencia, carecemos de controles generales sobre la aplicación de las medidas, lo que resulta agravado por la excesiva flexibilidad en la interpretación de quienes las están aplicando. Para ilustrar la afirmación anterior encontramos un ejemplo: la resolución 1973 (2011),

lution exigeant' l'unanimité des membres permanents, un membre permanent doit émettre un vote négatif. La procédure suivie par le Conseil de sécurité, qui est demeurée inchangée après l'amendement apporté à l'article 27 de la Charte en 1965, a été généralement acceptée par les Membres des Nations Unies et constitue la preuve d'une pratique générale de l'organisation”. Véase CIJ, Recueil 1971, p. 22.

57 Marchisio, S., L'ONU. Il diritto delle Nazioni Unite, Il Mulino, 2000, p. 191.

58 Es el caso del Comité de la Resolución 1540 (2004), o el comité de lucha contra el terrorismo, creado en aplicación de la resolución 1373 (2001) y 1624 (2005). 
del 17 de marzo, en virtud de la cual el Consejo de Seguridad "autoriza a los Estados miembros que hayan notificado previamente al Secretario General... adopten todas las medidas necesarias" para la protección de los civiles libios "excluyendo el uso de una fuerza de ocupación extranjera de cualquier clase y en cualquier parte del territorio libio"; así como el establecimiento de una zona de prohibición de vuelos autorizando para ello igualmente todas las medidas necesarias. ${ }^{59}$

Esta resolución desencadenó las operaciones desarrolladas en Libia. En aplicación de este texto no sólo se han bombardeado instalaciones militares libias, también se han producido otro tipo de actuaciones que nada tienen que ver con la letra de la resolución. El primer día de mayo la prensa nos informaba del bombardeo a la casa del hijo pequeño de Gadafi que produjo su muerte y la de tres de los nietos del dictador, acción que difícilmente puede fundamentarse sobre la protección de civiles libios o el establecimiento de una zona de exclusión aérea. ${ }^{60}$ Claro que depende de lo que entendamos por protección de civiles, pues la ministra de asuntos exteriores española a finales de marzo afirmaba que el único modo de proteger a los civiles libios era la salida de Gadafi del poder, ${ }^{61}$ por lo que cualquier medida que pudiera conducirnos a este resultado podría encajar dentro del alcance de aquella resolución.

Sin embargo, considero que las interpretaciones tan extensivas de estas autorizaciones deberían ser fruto de control por parte del Consejo de Seguridad, en su calidad de autor de aquellas, debe ser capaz de indicar hasta donde alcanza su autorización y sancionar los excesos. Lo contrario es aportar el punto de partida y desentenderse del problema que está provocando destrucción, caos y muerte en el territorio cuya población pretendemos proteger y, que a día de hoy, contempla como único procedimiento de protección, la huida del país.

Es cierto que los problemas derivados de la ausencia de control sobre la aplicación de las medidas autorizadas por el Consejo de Seguridad, como avanzaba al inicio, no son novedosos, ya los advertimos con

59 Contenidos que figuran respectivamente en los parágrafos 4 y 5-6, estos últimos relativos a la zona de exclusión aérea.

${ }^{60}$ Véase noticia difundida por agencias de prensa, por ejemplo, Agencia EFE, 1o. de mayo de 2011 .

${ }_{61}$ Véase palabras de 29 de marzo en http://www.rtve.es. 
la aplicación de la resolución 678 (1990), de 29 de noviembre, en la que se autorizaba el uso de la fuerza para volver a la situación anterior al 2 de agosto de 1990: la salida de Iraq del territorio anexionado de Kuwait. La aplicación de esta resolución provocó la famosa frase de Javier Pérez de Cuellar, entonces secretario general de las NU, afirmando que se trataba de una guerra autorizada por el Consejo de Seguridad, pero no era una guerra de las NU. ${ }^{62}$ En todo caso, la antigüedad en el planteamiento no impide la necesidad de buscarle remedio.

\section{LAS POSIBLES SOLUCIONES: EL CONTROL DE LEGALIDAD DE LAS DECISIONES DEL CONSEJO DE SEGURIDAD}

Vistos en las páginas anteriores algunos de los problemas que suscita la acción del Consejo de Seguridad en los últimos 21 años, en adelante, vamos a referirnos a las posibles soluciones a aplicar con el propósito de evitar sus efectos adversos. Para ello, hemos de partir de dos premisas: una, la presunción (iuris tantum) de validez de las decisiones de los órganos de las NU, como ha reiterado la CIJ en su jurisprudencia; ${ }^{63}$ otra, la imposibilidad jurídica de sostener que el Consejo de Seguridad permanezca ajeno a control de legalidad ${ }^{64}$ alguno, en la medida en que se trata de "un órgano de una Organización que ha sido creada en un marco jurídico específico (el Tratado constitutivo de dicha Organización)" ${ }^{65}$ En este último sentido, aún en ausencia de controles expresamente establecidos en la Carta de NU, es evidente que existen límites al ejercicio de competencias por parte del Consejo de Seguridad que ha de respetar.

${ }^{62}$ Véase entrevista a J. Pérez de Cuéllar en el diario El País del 24 de febrero de 1991, en http: / / www.elpais.com.

63 El juez Shahabuddeen se refiere a la presunción de validez de estos comportamientos como un principio general en la Opinión Consultiva relativa a las Consecuencias jurídicas para los Estados de las presencia continua en África del Sur en Namibia (Sudoeste africano) no obstante la resolución 279 (1970), del Consejo de Seguridad, CIJ, Recueil 1971, p. 22, par. 20.

${ }^{64}$ Sobre el control de legalidad, véase Torrecuadrada, S., "El control de legalidad de las decisiones del Consejo de Seguridad”, Agenda Internacional, PUCP, 2010, pp. 137 y ss.

65 Véase en Remiro, A. et al., Derecho internacional, Madrid, McGraw Hill, 1997, p. 953. 
En todo caso, descartamos como remedio la reforma de la Carta. Es cierto que si el texto constitutivo de NU ha dejado de adecuarse a la realidad social, la reacción lógica sería su adaptación a las necesidades actuales de la sociedad internacional. Modificación que, en la situación en presencia, podría tener una doble funcionalidad: por una parte dotar al Consejo de Seguridad de todos los poderes que se arroga, y, de modo muy especial, por otra, incorporar los contrapesos necesarios para que su actuación resulte cuando menos adecuada a la norma que perfila sus competencias.

El procedimiento de reforma de la Carta (previsto en su artículo 109.2) es esclavo de la arquitectura de la Organización y, en ese sentido, incluye el derecho de veto de los miembros permanentes del Consejo de Seguridad. Convengamos en este punto que los titulares de ese poder, previsiblemente sean firmes defensores de la primera vertiente apuntada (dotar al Consejo de los poderes que se atribuye), e intentarán evitar la segunda (establecimiento de controles), rechazando la pérdida de privilegios con los que cuentan, sin que sea uno de los menores entre ellos, la posibilidad de utilizar el Consejo de Seguridad y, en concreto el Capítulo VII de la Carta, a su antojo (o al menos intentarlo) sin verse constreñidos por posibles controles. En todo caso, los trabajos emprendidos con este propósito nos entretienen, pero desde hace más de 20 años no incorporan esta posibilidad.

Mientras la modificación se produce, y en ausencia de disposiciones en la Carta sobre el control de legalidad, podemos mantener aquellos con los que contamos. Para lo que distinguiremos entre los mecanismos internos a la propia organización y externos a la misma. Comenzaremos por el derecho de veto, modalidad de control directa e interna al órgano, que ha impedido en muchos casos no sólo que el Consejo adoptase decisiones en el estricto cumplimiento de sus funciones y competencias. También podemos identificar controles indirectos que siendo internos a la Organización son externos al órgano objeto de control, y en este punto encontraremos la relación entre el Consejo de Seguridad y la CIJ. Como ejemplo de control externo nos detendremos en el que han ejercido supervisando su aplicación, por una parte el Tribunal de Justicia de la Unión Europea (en adelante TJUE) y, más recientemente, el Tribunal Europeo de Derechos Humanos (en adelante TEDH) 


\section{Control interno: el derecho de veto}

El derecho de veto se incorpora en la Conferencia de Dumbarton Oaks en 1944, en la que el gobierno de Estados Unidos "sentó las bases de lo que sería el derecho de veto de los miembros permanentes del Consejo de Seguridad, sin que existiese oposición por parte del resto de las potencias", ${ }^{66}$ haciendo depender su membresía de la nueva Organización Internacional precisamente de la incorporación en la Carta del derecho de veto $^{67}$ (finalmente pactado en la Conferencia de Yalta) y de su titularidad.

El derecho de veto, sea individual o colectivo (la reunión de un número suficiente de miembros no permanentes que impiden el logro del umbral de adopción de decisiones), ha servido, durante mucho tiempo, para proteger los intereses de los miembros permanentes del Consejo de Seguridad, pero también ha tenido utilidad como control de legalidad de las decisiones adoptadas en su seno. Sin embargo ya no se utiliza para esos fines, recordemos la resolución 687 del Consejo de Seguridad, con relación a la cual, los miembros de este órgano pusieron de manifiesto sus dudas, pero votaron a favor de ella o se abstuvieron apelando a la excepcionalidad de la situación. ${ }^{68}$

66 Sobre el derecho de veto, véase Torres Cazorla, I., "El derecho de veto en el Consejo de Seguridad de NU: la historia de la válvula de seguridad que paralizó el sistema”, Anuario Colombiano de Derecho Internacional, Bogotá, 2008 pp. 49-88. El entrecomillado del texto se encuentra en la página 51.

${ }^{67}$ Véase un cuadro actualizado de los ejercicios del derecho de veto en el Consejo de Seguridad en http: / /www.globalpolicy.org/security-council/tables-and-charts-on-the-security-council-0 -82 /subjects-of-un-security-council-vetoes. html

68 Es el caso de Ecuador (véase su opinión en S/PV.2981, pp. 105 y ss.), India (tras apelar a la singularidad del caso, afirmaba la falta de legitimidad del Consejo de Seguridad para imponer por la autoridad del Capítulo VII de la Carta la solución a un conflicto regional), Zimbabwe (lo extraordinario del conflicto requiere soluciones extraordinarias), ambas opiniones pueden consultarse en S/PV.2981, pp. 56 y ss., especialmente pp. 72-80. Incluso el representante de los Estados Unidos reitera esos términos afirmando que la resolución se ajustaba a la singularidad de las circunstancias que rodearon el conflicto, o el de la (todavía) URSS apelando a la vertiente ejemplarizante de la resolución. Véase la intervención del representante de los Estados Unidos después de la votación en S/PV.2981, pp. 82-91, en ella justifica la aprobación de la resolución en criterios de justicia sin mencionar en absoluto la legalidad en la actuación del Consejo de Seguridad en este punto. 
En todo caso, observemos que el control sobre la legalidad de las decisiones del Consejo de Seguridad mediante el ejercicio del derecho de veto, ha de realizarse en la reunión de este órgano y en el momento de adopción de la decisión en cuestión, sin que sirva a estos propósitos, las críticas de un miembro permanente fuera de esta sala. Así, el 1o. de mayo de 2011, cuando se facilitaba la noticia del fallecimiento del hijo pequeño de Gadaffi y de tres de sus nietos, se acompañaba con la condena del Parlamento Ruso por el exceso en la aplicación de la resolución 1973, ${ }^{69}$ en la que aquella acción presuntamente encontraba fundamento.

\section{Control externo al órgano pero interno a la organización: la CIJ}

El segundo mecanismo de control antes anunciado es el que siendo externo al propio órgano cuyas decisiones se cuestionan, es interno a la organización a la que pertenece: el que puede ejercer la CIJ. Se trataría de un control judicial o cuasi judicial, en función de la jurisdicción (contenciosa o consultiva) que ejerza el órgano judicial principal de la Organización.

La Carta de NU no dota a órgano alguno de competencia general para interpretar los poderes de los demás, permaneciendo el control de cada uno de ellos en un ámbito estrictamente interno (autocontrol), evidenciado en el caso de la CIJ en el artículo 36.6 del Estatuto. ${ }^{70}$ Esta situación de descentralización puede provocar dispersión, como afirma M. Bedjaoui. ${ }^{71}$

La Carta carece de una atribución competencial a la Corte para ejercer un control de legalidad sobre las decisiones del Consejo de Seguridad. Esta ausencia no impide ese ejercicio de modo indirecto, en el

69 Véase noticia en El País del 1o. de mayo de 2011, en http: / / www.elpais.com/articulo/inter nacional/television/libia/muestra /supuesto/cadaver/Saif/Arab/elpepuint/20110501 elpepuint_2/ Tes.

70 Pozo, P., "La CIJ y las competencias del Consejo de Seguridad en el ámbito del mantenimiento de la paz y seguridad internacionales”, Anuario de Derecho Internacional, núm. 14, 1998 , pp. 417 y ss., afirmación citada en texto es p. 460.

${ }_{71}$ M. Bedjaoui, Nouvel ordre mondiale et contrôle de la légalité des actes du Conseil de Sécurité, Bruselas, Bruylant, 1994, p. 21; existe una versión inglesa de esta obra que lleva por título The NewWorld order and the Security Council. Testing the Legality of its Acts, Martinus Nijhoff, 1995. 
curso de un procedimiento contencioso o consultivo en presencia..$^{72}$ Por otra parte, no podemos olvidar que está obligada a conocer de las controversias (y a responder de las cuestiones) que se le sometan salvo que, en ejercicio de "la competencia de la competencia", decida su improcedencia, en su defecto no puede resistirse al ejercicio de la jurisdicción (36.6 del Estatuto). Sus normas reguladoras le impiden la discrecionalidad en el ejercicio de sus funciones, así el artículo 36.1 de su Estatuto afirma su competencia en relación a "todos los litigios que las partes le sometan", el artículo 38 reitera este contenido, estableciendo "La Corte, cuya misión es arreglar conforme al derecho internacional que se le sometan...". Obligación de conocer que la misma Corte, en su jurisprudencia, ha reiterado.

El alcance de esa obligación no es absoluta así, en el caso de Camerún Septentrional, la CIJ indicó los límites al ejercicio de su jurisdicción (contenciosa o consultiva), entre los que no figura el supuesto de control indirecto de las resoluciones del Consejo de Seguridad. ${ }^{73}$ En conse-

72 En este sentido se expresó M. Rezek en la opinión individual que redactó en el caso Lockerbie afirmando que la Corte es «...l'interprète par excellence du droit et le for naturel de la revision, au nom du droit, des actes des organes politiques, tel qu'il est de rigueur dans les régimes démocratiques. Ce serait bien une source d'étonnement si le Conseil de sécurité des Nations Unies devait jouir d'un pouvoir absolu et incontestable à l'égard de la règle de droit, privilège dont ne jouissent pas, en droit interne, les organes politiques de la plupart des fondateurs et des autres membres de l'organisation, à commencer par 1'Etat défendeur. C'est aux Etats Membres des Nations Unies, au sein de l'Assemblée générale et du Conseil de sécurité, qu'appartient le pouvoir de légiférer, de changer s'ils le veulent les règles qui président au fonctionnement de l'organisation. Dans l'exercice de la fonction législative, ils peuvent décider, par exemple, que l'organisation peut se passer d'un organe judiciaire, ou que celui-ci, contrairement aux modèles nationaux, n'est pas l'interprète ultime de l'ordre juridique de l'organisation, lorsque se pose la question de la validité d'une décision d'un autre organe du système». Véase la Opinión a la Sentencia de 27 de febrero de 1998 (Libia c. Estados Unidos de América, p. 154) (Libia c. Reino Unido, p. 63)

73 El listado no es muy extenso, se reduce a las cuatro categorías siguientes: 1) incompatibilidad entre las pretensiones de las partes (Ordenanza de 19 de agosto de 1929 (CPJI, serie A, núm. 22, p. 15)); 2) cuando las partes hacen depender la validez de la eventual Sentencia de la aprobación posterior de las partes (Asunto Zonas Francas, Serie A/B, núm. 46, p. 1); 3) cuando las partes plantean cuestiones "mal adaptadas al papel de un tribunal de justicia", y cuando se pide a la Corte que decida entre las distintas alternativas de posible aplicación a la controversia. En el Caso Haya de la Torre se solicitaba a la Corte la indicación de los medios para poner fin al asilo diplomático del Sr. Haya de la Torre, la respuesta fue meridianamente clara: "estas vías se condicionan por elementos y posibilidades que, en gran medida, las Partes 
cuencia, no existirían impedimentos jurídicos al control de la legalidad de las resoluciones del Consejo, por la CIJ aunque carecemos de práctica al respecto. Estuvimos muy próximos a contemplar el primer supuesto de ejercicio de ese control en el asunto de Lockerbie, en el que el demandante dudaba de que los hechos ${ }^{74}$ pudieran calificarse como una amenaza para la paz, un quebrantamiento de la paz o un acto de agresión. Libia solicitaba que la CIJ interpretase "in accordance with the Charter, which determined their validity"75 las resoluciones 748 (1992) y 883 (1993), adoptadas con fundamento en el Capítulo VII de la Carta, después del depósito de la demanda, pero antes de la sustanciación de la fase preliminar.

El argumento de la superioridad jerárquica de las resoluciones del Consejo de Seguridad derivada de la interpretación conjunta de los artículos 25 y 103 de la Carta, no es determinante con relación a las sentencias que pueda emitir la CIJ. Ello es así puesto que el artículo 103 puede utilizarse también como comodín para dotar de esa superioridad jerárquica a los fallos de la Corte (que no a las opiniones consultivas que no resultan jurídicamente obligatorias ni para el órgano que las formuló), mediante su adición al artículo 94 de la Carta, referido a la obligatoriedad de las sentencias dictadas por la Corte en los procedimientos contenciosos. De este modo, las sentencias de la Corte y las resoluciones del Consejo de Seguridad se encuentran en idéntico plano.

son las únicas en situación de apreciar. Una elección entre ellas no podría fundarse sobre consideraciones jurídicas, sino solo por consideraciones de naturaleza práctica o de oportunidad política, lo que no entra en la función judicial de la Corte efectuar esta elección”. Véase la sentencia de 13 de junio de 1951 en el asunto Haya de la Torre, en CIJ Recueil 1951, pp. 78-79.

74 Recordemos que el hecho que provocó la acción del Consejo de Seguridad fue la negativa Libia a entregar a los demandantes a dos de sus nacionales, presuntos causantes de la explosión del avión de la PAN-AM sobre la ciudad escocesa de la que el caso toma su denominación. La duda es si puede calificarse este comportamiento como una amenaza para la paz, un quebrantamiento de la paz o un acto de agresión. De la respuesta a esta cuestión depende la legalidad o no de la actuación del Consejo de Seguridad y, en todo caso, para establecer la responsabilidad libia en ese acto terrorista resultaba imprescindible que los dos nacionales libios hubieran cometido sus crímenes actuando por cuenta y bajo la dirección del Estado o que sus actos se hubieran confirmado por el Estado como propios. Este argumento lo utiliza el juez El-Kosheri, en su opinión disidente a la Ordenanza del 14 de abril de 1992, parágrafo 9, p. 202.

75 Es el parágrafo 42 de la sentencia de Lockerbie (Libia c. Reino Unido). 
Sin embargo, esta afirmación ha de matizarse debido al diferente alcance subjetivo de unos actos y otros. Así, las sentencias de la CIJ sólo son jurídicamente obligatorias para los Estados partes en la diferencia concreta y exclusivamente respecto del asunto que se sometió a conocimiento de la Corte (ex artículo 94 de la Carta y artículo 59 del Estatuto), frente a la generalidad de la formulación del artículo 25 de la Carta que alcanza dentro de su ámbito subjetivo a todos los miembros de la Organización. ${ }^{76}$

Finalmente, como es sabido, la Corte nunca llegó a pronunciarse sobre el fondo de este asunto porque las partes acordaron desistir en su continuación. ${ }^{77} \mathrm{~A}$ pesar de que el desistimiento impidió el ejercicio del control de legalidad por parte de la Corte sobre las resoluciones del Consejo de Seguridad, se puso de manifiesto la posibilidad de su materialización. Como afirmó, Ph. Weckel, el asunto de Lockerbie evidenció la impotencia de la CIJ frente al Consejo de Seguridad, ${ }^{78}$ no desde una perspectiva jurídica, pero sí claramente en cuanto al poder político de uno y otro órgano.

La CIJ también podría ejercer un control indirecto de legalidad de las decisiones del Consejo de Seguridad mediante su jurisdicción con-

76 Artículo 94.1: "Cada miembro de las NU se compromete a cumplir la decisión de la CIJ en todo litigio en que sea parte”. Artículo 59 del Estatuto de la CIJ: “La decisión de la Corte no es obligatoria sino para las partes en litigio y respecto del caso que ha sido decidido». Artículo 25 de la Carta: "Los miembros de las NU convienen en aceptar y cumplir las decisiones del Consejo de Seguridad de acuerdo con esta Carta”.

77 En la ordenanza de 10 de septiembre de 2003. Claro que, en esos cinco años no se había avanzado mucho en el procedimiento, tan solo se había cubierto la fase escrita con doble documentación, el último de los instrumentos escritos fue la dúplica estadounidense, presentada el 3 de agosto de 2001 (la británica se depositó dos días antes, el 1o. de agosto) sin que, en los dos años posteriores que transcurrieron antes de la eliminación del asunto del listado de los pendientes hubiera el menor amago de iniciar la fase oral del procedimiento. Curiosamente, si el 10 de septiembre el caso Lockerbie se borraba de la lista de los asuntos pendientes, el 12 del mismo mes se adoptó la resolución del Consejo de Seguridad (1506) en la que se levantaban las sanciones económicas impuestas once años antes a Libia como consecuencia del atentado. En el acta de la adopción de la resolución el representante estadounidense afirma el cumplimiento libio de las exigencias de NU, declarando, entre otros, aceptar su responsabilidad por las acciones de sus funcionarios y acordando la indemnización a las víctimas.

78 Weckel, Ph., "L'institution d'un Tribunal International pour la répression de droit humanitaire en Yougoslavie“, AFDI, 1993, pp. 232, 233-4 y ss. 
sultiva que tampoco está concebida para realizar este tipo de control de legalidad. ${ }^{79}$ Sin embargo, aunque el supuesto resulte altamente improbable, nada impediría que la Asamblea General formulara una cuestión jurídica a la Corte (según lo previsto en el artículo 96.1 de la Carta), o que autorizara a otros órganos y organismos internacionales a que lo hicieran siempre que las cuestiones jurídicas a plantear "surjan dentro de la esfera de sus actividades", es decir, siempre que indirectamente la legalidad de las resoluciones del Consejo afectaran al ámbito de las competencias otorgadas al órgano u organismo reclamante.

La hipótesis planteada no puede parecernos extraña pues existe un precedente claro: el que nos proporciona la Opinión Consultiva en el asunto de Namibia. En ella, la CIJ se pronunció sobre la legalidad de las resoluciones del Consejo de Seguridad, afirmando conformidad de los parágrafos 2 y 5 de la resolución 276 (1970), del parágrafo 3 de la resolución 264 (1969) y del parágrafo 5 de la resolución 269 (1969) con los “fines y principios de la Carta y a sus artículos 24 y 25", declarando, en consecuencia la obligatoriedad de las resoluciones indicadas para todos los Estados miembros de las NU. ${ }^{80}$ Por lo demás, el mismo Tribunal, en su opinión sobre el muro en Israel, consideró que, en ejercicio de su jurisdicción, puede controlar la legalidad de los actos realizados por los otros órganos de las NU, ya que 'C' est à la Cour qu'il appartient de s'assurer que la demande d'avis consultatif émane d'un organe ou d'une institution ayant compétence pour ce faire". ${ }^{81}$

Sin embargo, el ejercicio indirecto de control de legalidad de las decisiones del Consejo de Seguridad por la jurisdicción consultiva de la CIJ, suscita un problema añadido: los legitimados para formular la cues-

79 La Corte en el asunto de Namibia (en CIJ, Recueil 1971, parágrafo 89) ya afirmaba "Il est évident que la Cour n'a pas de pouvoirs de contrôle judiciaire ni d'appel en ce qui concerne les décisions prises par les organes des Nations unies dont il s'agit".

80 Véase El parágrafo 89 de la Opinión Consultiva de 21 de junio de 1971, CIJ, Recueil 1971, redactado en los siguientes términos: “Cependant, dans l'exercice de sa fonction judiciaire et puisque des objections ont été formulées, la Cour examinera ces objections dans son exposé des motifs avant de se prononcer sur les conséquences juridiques découlant de ces résolutions".

81 Véase el parágrafo 15 de la Opinión Consultiva del 9 de julio de 2004, sobre las consecuencias jurídicas de la construcción de un muro en el territorio palestino ocupado, en CIJ, Recueil 2004. 
tión jurídica. Entran dentro de esta categoría tanto la Asamblea General como el Consejo de Seguridad (artículo 96.1 de la Carta) y «otros órganos de la Organización e instituciones especializadas» con una capacidad de consulta materialmente limitado al ámbito de sus competencias y previamente autorizados por la Asamblea (artículo 96.2 de la Carta). Precisamente aquí radica el problema, dado que si pretendemos controlar la legalidad de las decisiones del Consejo de Seguridad, no será éste quien plantee la cuestión y, en el resto de los casos, se cuestiona si la Asamblea General se vería limitada por el artículo 12 de la Carta. ${ }^{82} \mathrm{De}$ ser así, estaríamos blindando al Consejo frente a esta posibilidad, dado que la prohibición alcanzaría tanto a la formulación por la Asamblea de la cuestión consultiva como a la autorización a otros órganos a estos efectos.

Algunos autores defienden la aplicación del artículo 12 de la Carta a la formulación de cuestiones jurídicas a la Corte. ${ }^{83}$ Sin embargo, la interpretación conjunta de los artículos 11 y 12 de la Carta, como indica Sh. Rosenne, ${ }^{84}$ se limitaría a los poderes de acción, al afirmar que las cuestiones sobre mantenimiento de la paz y la seguridad internacionales "con respecto a la cual se requiera acción será referida al Consejo de Seguridad por la Asamblea General antes o después de discutirla” (artículo 11). Es evidente que el planteamiento de una cuestión a la Corte no implica acción, por lo que cabría esa posibilidad, a pesar de lo que inicialmente parece desprenderse del literal de estos preceptos de la Carta.

Por otra parte, C. Espósito defiende que la Asamblea General podría solicitar dictámenes consultivos incluso en supuestos en los que resulte de aplicación el artículo 12.1 de la Carta. Ello es así, al entender que el planteamiento de una cuestión jurídica a la Corte "no constituye una

82 Recordemos el tenor del artículo 12.1 es el siguiente: "Mientras el Consejo de Seguridad esté desempeñando las funciones que le asigna esta Carta con respecto a una controversia o situación, la Asamblea General no hará recomendación alguna sobre tal controversia o situación, a no ser que lo solicite el Consejo de Seguridad”.

${ }_{83}$ Es el caso de S. Rosenne, The Law and Practice of the International Court, Leyden, 1965, 2 vols., p. 73; D. Pratap, The Advisory Jurisdiction of the International Court, Oxford, 1972, p. 57 o P. Benvenuti, L'accertamento del diritto mediante i parere consultivi della Corte Internazionale di Giustizia, Milán, 1985, p. 116.

${ }^{84}$ Véase Sh. Rosenne, op.cit., p. 57. 
recomendación en el sentido de la norma en cuestión". ${ }^{85}$ Lo anterior no impide a la Asamblea la autorización a otros órganos para que, dentro de su ámbito material de competencias, formule a la Corte las preguntas que considere oportunas.

Comprobamos que los posibles controles de legalidad ejercidos por la CIJ, debido a su carácter indirecto, resultan claramente insuficientes a los propósitos que nos planteamos aquí, pues para ello dependemos de la existencia de una controversia interestatal o del planteamiento de una cuestión jurídica y de que para pronunciarse sobre aquella la Corte precise pronunciarse sobre la legalidad de la resolución o respuesta.

\section{Control externo al órgano y a la organización: el Tribunal de Justicia de la Unión Europea (TJUE) y el Tribunal Europeo de Derechos Humanos (TEDH)}

El último mecanismo de control que planteamos es el ejercido por órganos ajenos a la organización, que han de controlar la aplicación de las resoluciones del Consejo de Seguridad. En este punto nos centraremos en dos de ellos: el TJUE y el TEDH.

\section{A. El control ejercido por el TJUE}

Para ilustrar la posibilidad apuntada contamos con la práctica delTJUE, cuya primera instancia dictó una sentencia el 21 de septiembre de $2005,{ }^{86}$ relacionada con la aplicación de una resolución del Consejo de

85 Espósito, C., La jurisdicción consultiva de la CIJ, McGraw Hill, Madrid, 1996, pp. 65 y 66.

86 Sobre el asunto que da origen a ambas sentencias y el contenido de las mismas se ha escrito mucho y muy bien, entre las obras que analizan la primera de las sentencias, véase: Roldán Barbero, J., “Jurisprudencia en materia de derecho internacional público: la justicia comunitaria y el control de legalidad de las resoluciones del Consejo de Seguridad de NU. Comentario a las Sentencias Yusuf/al Barakaat y Kadi, de 21.9.05, del Tribunal de Primera Instancia de las Comunidades Europeas”, REDI, vol. 57, núm. 2, 2005, pp. 869-891; Blázquez Navarro, I. y Espósito Massicci, C.,D., "Los límites al control judicial de las medidas de aplicación de la política exterior en los asuntos Ahmed Ali Yusuf/Al Barakaat International Foundation y Yassin Abdullah Kadi”, Revista Española de Derecho Europeo, núm. 17, 2006, pp. 123-148; Bore Eveno, V., "Le contrôle juridictionnel des résolutions du Conseil de Sécurité; 
Seguridad, recurrida en casación originando la sentencia de la Gran Sala del Tribunal de Justicia de 3 de septiembre de 2008. ${ }^{87}$

El caso en el que encuentra origen el asunto es la Resolución 1267 (1999) del Consejo de Seguridad que establece un Comité encargado de recabar y considerar información sobre la aplicación por los Estados de las medidas decididas por aquel órgano principal de NU, con el objeto de perseguir el terrorismo y, concretamente, supervisar la aplicación de la resolución antes citada. Al año siguiente, el mismo órgano principal adopta la resolución 1333 (2000) en la que se amplía el mandato de este órgano subsidiario al solicitarle la actualización del listado mediante la (8.c) "información suministrada por los Estados y organizaciones regionales, de las personas y entidades que se haya indicado que están asociadas con Usama bin Laden, incluidas las de la organización Al-Qaida”. ${ }^{88}$

vers un constitutionnalisme international?", Révue Générale de droit international public, vol. 110, núm. 4, 2006, pp. 827-860; Karayigit, M. T., "The Yusuf and Kadi Judgments. The Scope of the EC Competences in respect of Restrictive Measures", Legal Issues of Economic Integration, vol. 33, núm. 4, 2006, pp. 379-404; Tomuschat, Ch., "Court of Justice: Case T-306/01, Ahmed Ali Yusuf and Al Barakaat International Foundation v. Council and Commission; Case T-315/01, Yassin Abdullah Kadi v. Council and Commission”, Common Market Law Review, vol. 43, 2006, pp. 537-551.

87 Sobre la Sentencia del TJ véase Hinojosa, L. M., "Bad Law for Good Reasons: The Contradictions of the Kadi Judgment”, en International Organizations Law Review, núm. 5, 2008, pp. 1-19; Ripol Carulla, S., "Los asuntos 'Kadi, Yusuf, Chafiq Ayadi': cuestiones de derecho internacional”, Revista Vasca de Administración Pública, núm. 82-2, 2008, pp. 253-274; Santos Vara, J., "El control judicial de las sanciones contra Al-Qaeda y los talibanes en la Unión Europea: ¿un desafío a los poderes del Consejo de Seguridad?", Revista de Derecho Comunitario Europeo, núm. 32, 2009, pp. 91-120; Jiménez García, F., "Tutela Judicial efectiva, pilares intergubernamentales de la Unión Europea y NU o viceversa. El periplo comunitario marcado por los asuntos Yusuf/Kadi, Avadi/Hassan, Modjahedines del pueblo de Irán y Segi/Gestoras”, en Cuerda Riezu, A. R. y Jiménez García, F. (coords.), Nuevos desafíos del derecho penal internacional: terrorismo, crímenes internacionales y derechos fundamentales, Madrid, Tecnos, 2009, pp. 411-464; Sanfrutos Cano, E., "Unión Europea: Comentario a la STJCE de 3 de septiembre de 2008 en los asuntos acumulados C-402/2005 P y C-415/2005 P,Yassin Abdullah Kadi y Al Barakaat International Foundation c. Consejo y Comisión”, Gaceta jurídica de la Unión Europea y de la competencia, núm. 7, 2009, pp. 69-82; Burca, G., "The European Court of Justice and the International Legal Order after 'Kadi'”, en Harvard International Law Journal, vol. 51, núm. 1, 2010, pp. 1-49, entre otras.

88 Poco después, mediante la resolución 1390 (2002), pide la actualización periódica de la relación, para (en la resolución 1455 (2003)), pedir “al Comité que comunique a los Estados 
Ese listado debía transmitirse a los Estados miembros para que se procediera a la congelación de los fondos y activos financieros de quienes aparecieran en la relación, confeccionada por procedimientos nada garantistas de los derechos individuales. ${ }^{89}$ Para aplicar en la Unión Europea (en adelante UE) las resoluciones del Consejo que imponían esos comportamientos, siempre que los fondos y recursos bloqueados pertenecieran o los mantuviera una persona física o jurídica que figurase en la relación confeccionada por aquel Comité 1267, el Consejo de la UE, adoptó sobre la base de los artículos $60^{90}$ (libre circulación de capitales y pagos), $301^{91}$ y $308^{92}$ (competencia residual) del Tratado de la Comu-

Miembros, al menos cada tres meses, la lista mencionada en el párrafo 2 de la resolución 1390 (2002) y subraya a todos los Estados Miembros la importancia de presentar al Comité, en la medida de lo posible, los nombres de los miembros de la organización Al-Qaida y de los talibanes y de otras personas, grupos, empresas y entidades a ellos asociados, así como los datos que sirvan para su identificación, de forma que el Comité pueda considerar la inclusión de nuevos nombres y detalles a su lista, a menos que ello redunde en perjuicio de las investigaciones o las medidas coercitivas".

89 Sobre el procedimiento para la elaboración de la lista en cuestión, véase L.M. Hinojosa, "Las sanciones del Consejo de Seguridad contra Al Qaeda y los talibanes ¿son realmente inteligentes?”, Revista Española de Derecho Internacional, vol. 58, 2006-2, pp. 737 y ss., especialmente p. 742 .

90 "Cuando sea necesario para lograr los objetivos enunciados en el artículo 67, en lo que se refiere a la prevención y lucha contra el terrorismo y las actividades con él relacionadas, el Parlamento Europeo y el Consejo definirán mediante reglamentos, con arreglo al procedimiento legislativo ordinario, un marco de medidas administrativas sobre movimiento de capitales y pagos, tales como la inmovilización de fondos, activos financieros o beneficios económicos cuya propiedad, posesión o tenencia ostenten personas físicas o jurídicas, grupos o entidades no estatales". Tras la entrada en vigor del Tratado de Lisboa, este contenido se encuentra en el artículo 75 del Tratado de Funcionamiento de la UE.

91 “Cuando una posición común o una acción común, adoptadas con arreglo a las disposiciones del Tratado de la Unión Europea relativas a la política exterior y de seguridad común, impliquen una acción de la Comunidad para interrumpir o reducir parcialmente o en su totalidad las relaciones económicas con uno o varios terceros países, el Consejo adoptará las medidas urgentes necesarias. El Consejo decidirá por mayoría cualificada a propuesta de la Comisión”. Tras la entrada en vigor del Tratado de Lisboa, ese contenido se ha transformado en el artículo 215.

92 "Cuando se considere necesaria una acción de la Unión en el ámbito de las políticas definidas en los Tratados para alcanzar uno de los objetivos fijados por éstos, sin que se hayan previsto en ellos los poderes de actuación necesarios a tal efecto, el Consejo adoptará las disposiciones adecuadas por unanimidad, a propuesta de la Comisión y previa aprobación del Parlamento Europeo. Cuando el Consejo adopte dichas disposiciones con arreglo a un 
nidad Europea, entonces vigente, el Reglamento 881/2002. Los nombres de Yassin Abdullah Kadi y Al Barakaat International Foundation, se mencionaban en el Anexo 1 del Reglamento (en el que se incorporaba la relación), quienes interpusieron un recurso de anulación del reglamento alegando las violaciones del derecho de defensa, pues no se les permitió participar en forma alguna en el procedimiento tendente a su incorporación a aquel listado, el derecho a la propiedad privada, pues sus bienes se encontraban bloqueados, impidiéndoseles el acceso a ellos y al derecho a la tutela judicial efectiva.

El Tribunal de Primera Instancia (en adelante TPI) en su Sentencia (de 12 de diciembre de 2006), desestimó la acción por falta de jurisdicción para revisar la legalidad del acto entendiendo que las instituciones comunitarias carecen de competencia tanto para modificar el contenido de las resoluciones del Consejo como para poner en marcha un mecanismo susceptible de modificarlas, subrayando la prioridad de la seguridad y las medidas para luchar contra el terrorismo sobre la protección de los derechos humanos que, en consecuencia, se ven restringidos. ${ }^{93}$

La sentencia del TPI fue recurrida en casación, dando lugar a que el TJUE, se pronunciara al respecto en la del 3 de septiembre de 2008, anulando la sentencia del TPI y el Reglamento 881/2002 que permitía la aplicación de la resolución del Consejo de Seguridad en el territorio UE. El TJUE afirmaba entonces que:

... las jurisdicciones comunitarias deben, conforme a las competencias de las que el TCE les enviste, asegurar un control, en principio completo, de la legalidad del conjunto de los actos comunitarios a la vista de los derechos fundamentales, haciendo parte integrante de los principios generales del derecho comunitario,

procedimiento legislativo especial, se pronunciará también por unanimidad, a propuesta de la Comisión y previa aprobación del Parlamento Europeo”. En la actualidad, tras la entrada en vigor del tratado de Lisboa este contenido se encuentra en el artículo 352.

93 Así, el parágrafo 214 establece que: «todo control de la legalidad interna del reglamento atacado, especialmente a la vista de las disposiciones o los principios generales de derecho comunitario relativos a la protección de los derechos fundamentales implicaría que el tribunal examinara, de forma incidental, la legalidad de esas resoluciones. En la hipótesis en que como consecuencia del examen, se concluyera la ilegalidad, invocada por el requirente debería buscarse no en la adopción del reglamento atacado, sino en las resoluciones del Consejo de Seguridad que ha decretado las sanciones». 
incluso sobre los actos comunitarios que, como ocurre con el reglamento litigioso, pretende aplicar las resoluciones adoptadas por el Consejo de Seguridad en virtud del Capítulo VII de la Carta. ${ }^{94}$

Esta revisión de la validez de cualquier acto comunitario a la luz de los derechos fundamentales "debe considerarse como la expresión, en una comunidad basada en el imperio de la Ley, de una garantía constitucional derivada del TCE como un sistema jurídico autónomo, que es a no ser perjudicados por un acuerdo internacional", ${ }^{95}$ priorizando, en consecuencia, la línea de la protección de los derechos humanos.

El TJUE insiste en que "el control de la legalidad que debe ser asegurado por el juez comunitario alcanza el acto comunitario tendente a poner en práctica el acuerdo internacional en causa y no este último en tanto que tal". El Tribunal dejó claro que los tribunales comunitarios carecen de facultades para revisar la legalidad de las resoluciones aprobadas por el Consejo de Seguridad en virtud del Capítulo VII de la Carta "incluso si esa revisión se limita al examen de la compatibilidad de esa resolución con el ius cogens". ${ }^{96}$

Por lo demás, el TJUE destacó el principio de la primacía de las obligaciones derivadas de la Carta de NU. Aunque una eventual sentencia dictada por el juez comunitario decidiera que "una medida comunitaria destinada a dar efecto a una resolución tal es contraria a una norma superior del orden jurídico comunitario no implicaría un cuestionamiento de la primacía de esa resolución en el plano internacional”, pero sí en el comunitario e impediría su aplicación. ${ }^{97}$

En cuanto a los derechos vulnerados, estima que desde el momento en que

el Consejo no ha comunicado a los requirentes los elementos retenidos en su contra para fundar las medidas restrictivas que se les han impuesto ni ha acordado el derecho de darles conocimiento de dichos elementos en un plazo razonable tras la adopción de las medidas, los requirentes no pueden dar a conocer de forma útil

94 Es el parágrafo 326.

95 Idem.

96 Véase respectivamente los parágrafos 286 y 287.

97 Véase parágrafo 288. 
su punto de vista. En consecuencia, los derechos de defensa, en particular el de dejarse oír, no se ha respetado. ${ }^{98}$

El ejemplo puede servirnos para ilustrar la posibilidad planteada al inicio, más si cabe por cuanto, como indica la profesora Andrés Sáenz de Santamaría en Europa "se están cuestionando judicialmente con éxito las medidas de ejecución de las Resoluciones del Consejo”. ${ }^{99}$

\section{B. El control ejercido por el TEDH}

Recientemente, a comienzos del mes de julio de 2011, la Gran Sala del TEDH dictaba dos interesantísimas sentencias relacionadas con la aplicación de las resoluciones del Consejo de Seguridad (el demandado defendía su situación en el amparo proporcionado por sus resoluciones), por hechos acontecidos en el territorio de Iraq, atribuibles en ambos casos al Reino Unido. Se trata de los asuntos Al-Skeini y Al-Jedda. ${ }^{100}$ El primero de ellos se refiere a la muerte de seis nacionales iraquíes en Basora, zona bajo control de tropas británicas. En la sentencia se analizan las resoluciones del Consejo de Seguridad relativas a esta operación realizada por Estados Unidos, Reino Unido y sus aliados, sin más cobertura que la que, desde su punto de vista, les proporcionaba la resolución 1441 (2002), del 8 de noviembre.

Una de las cuestiones a dilucidar es si los británicos a los que resultan atribuibles los hechos actuaban en nombre y por cuenta de las Naciones Unidas, del gobierno iraquí o del Reino Unido. En este sentido, el TEDH se decanta por el último. Es cierto que los hechos se han cometido extraterritorialmente, pero también lo es que bajo su jurisdicción, pues "ses organes assument des fonctions exécutives ou judiciaires sur un territoire autre que le sien”, motivo por el cual "un Etat contractant

98 Véase parágrafo 348.

99 Sáenz de Santamaría, P. Andrés, "Sistema de listas y derechos humanos en las sanciones del Consejo de Seguridad: la perspectiva europea”, en Blanc Altemir, A. (ed.), El proceso de reforma de las NU, Madrid, Tecnos, 2009, 293 y ss. especialmente 312.

100 Respectivamente, asunto Al-Skeini y otros c. Reino Unido (demanda núm. 55721/07) y asunto Al-Jedda c. Reino Unido (demanda núm. 27021/08), ambas son sentencias de la Gran Sala del TEDH del mismo día: el 7 de julio de 2011. 
peut être tenu pour responsable des violations de la Convention commises dans l'exercise de ces fonctions, pourvu que les faits en question soient imputables à lui et non à l'Etat territorial”. ${ }^{101}$ Siendo así y dado que el Convenio Europeo de Derechos Humanos es un "instrument constitutionnel de l'ordre public européen”, ${ }^{102}$ los Estados partes en este texto convencional han de respetarlo en todo caso, con independencia del lugar en el que se desarrollen sus actividades.

En este caso, el TEDH considera que el Reino Unido ha vulnerado el artículo segundo del Convenio Europeo de Derechos Humanos de los familiares de los requirentes, fallecidos en territorio iraquí y, en concreto de la obligación procesal de aquel derivada "de conduire une enquête adéquate et effective sur le décès", además de condenar al Reino Unido a proveer una indemnización a los herederos de los fallecidos.

Por su parte, la sentencia en el asunto Al-Jedda, cuenta con un supuesto de hecho diferente, se trata de un ciudadano con doble nacionalidad (iraquí e irlandesa), detenido en Iraq por soldados británicos por suponer que reclutaba terroristas fuera de este Estado para que ejecutaran estos actos sangrientos en él, permaneciendo internado desde el 10 de octubre de 2004 hasta el 30 de diciembre de 2007, sin haber sido sometido a juicio y habiéndosele privado de su ciudadanía británica. De nuevo, el TEDH examina las resoluciones del Consejo de Seguridad, con el propósito de advertir en qué medida estos actos podrían restringir el alcance del derecho a la libertad y la seguridad, salvo en aplicación de una sentencia o para hacerle comparecer a juicio. El Tribunal considera que

l'autorisation donnée dans la Résolution 1511 n'a pase u pour effet de rendre imputables à l'ONU les actes des soldats de la forcé multinationale ni — aspect plus important aux fins de la presente affaire - de mettre fin à leur imputabilité aux Etats fournisseurs de contingents. ${ }^{103}$

\footnotetext{
101 Es el parágrafo 135 de la sentencia Al-Skeini citada en nota anterior.

102 Es el parágrafo 141 de la misma sentencia.

103 Es el inicio del parágrafo 80 de la Sentencia Al-Jedda, ya citada.
} 
Del mismo modo que en la sentencia Al-Skeini, el detenido había estado durante todo el tiempo en un centro de internamiento en Basora, ciudad controlada exclusivamente por las fuerzas armadas británicas, por lo que se encontraba bajo "l'autorité et contrôle du Royaume-Uni”. ${ }^{104}$ Por lo anterior, considera que los hechos son atribuibles al Reino Unido que ha vulnerado el artículo 5.1 del Convenio, dado que la detención preventiva “lorsqu'aucune poursuite pénale n’est envisagée dans un délai raissonable ne figurent pas parmi les motifs exhaustivement énumérés à l'article 5.1". ${ }^{105}$ Igual que en el caso anterior, procede la indemnización del Estado parte al requirente.

Es cierto que, hasta el momento, los controles realizados por estos dos tribunales (TJUE y TEDH) han sido los más eficaces que hemos contemplado, sin embargo, debido a su alcance regionalmente limitado, pues exclusivamente pueden actuar en relación con los comportamientos de la Organización o de sus Estados miembros en el caso de la UE, o de los que poseen el estatuto de partes en el Convenio Europeo de Derechos Humanos, de su ejercicio deriva un alcance muy limitado. En todo caso, es un ejemplo a seguir para evitar la impunidad de los comportamientos de los Estados que se escudan en el mandato de Naciones Unidas para actuar contraviniendo las obligaciones convencionales que, especialmente en materia de derechos humanos, no pueden olvidar.

\section{CONCLUSIONES}

Mediada la década de los noventa del siglo XX se establece un nuevo equilibrio interorgánico en la arquitectura de las NU que supuso el despertar del Consejo de Seguridad y, por su actuación, ha llegado a ser considerado por algunos como el representante de la comunidad internacional. A pesar de ello, este órgano principal de la Organización se ha plegado a la voluntad de uno de sus miembros permanentes que, solo ocasionalmente no ha visto materializados sus deseos y, cuando así ha

104 Ibidem, parágrafo 85.

105 Ibidem, parágrafo 100. 
ocurrido no duda en actuar de acuerdo con sus intereses (baste en este punto como ejemplo los bombardeos de la OTAN de 1999 y la agresión a Iraq de 2003), con más o menos compañía (pero sin contar con una resolución del Consejo que le permitiera hacerlo) contra un Estado que, según su consideración, incumplía las resoluciones de este órgano.

Es evidente que la competencia del Consejo de Seguridad cuando actúa como responsable primordial del mantenimiento de la paz y la seguridad internacionales no es absoluta. Sin embargo, la práctica de este órgano ignora la existencia de esos límites, en comportamientos ultra vires, excediéndose de su capacidad ya sea en la calificación del presupuesto necesario para la aplicación del sistema de seguridad colectiva; en la ubicación del fundamento jurídico que permita la acción que pretende adoptar (en el Capítulo VII en lugar de en el VI cuando se trata de resolver una controversia), o por el tipo de medidas decididas. Este tipo de comportamientos provoca la pérdida de la credibilidad del propio órgano y, por ende, a la Organización a cuya estructura pertenece. Convengamos que, en una sociedad internacional escasamente institucionalizada como la que poseemos, el efecto recién apuntado (la pérdida de credibilidad) no resulta, en absoluto, deseable.

Los comportamientos discutibles del Consejo de Seguridad proporcionan una imagen de paralegalidad que contribuye a deteriorar gravemente la imagen y credibilidad de un sistema que tanto ha costado construir.

En su defensa cabe alegar que el Consejo que es víctima de su misma arquitectura, más aún tras el final de la Guerra Fría, concluida con un claro vencedor que consigue lo que pretende con o sin el Consejo de Seguridad. Pero no podemos ignorar que la ausencia de controles de legalidad a las decisiones del Consejo contribuyen a facilitar la interpretación excesivamente flexible de sus poderes. Sin embargo, los trabajos de reforma de la Carta parecen, al día de hoy, más preocupados por otras cuestiones relacionadas con el Consejo de Seguridad (formación, derecho de veto...) que por las que hemos planteado en este punto. En todo caso, no olvidemos que cualquier modificación en este punto deberá contar con el consentimiento de los miembros permanentes del Consejo, que cuentan con derecho de veto en el procedimiento de reforma de la Carta (ex artículo 109.2). Esto difícilmente permite una 
adaptación de este órgano a las necesidades reales de la sociedad internacional contemporánea, si ello supone la pérdida de los privilegios con los que aquéllos cuentan. Por tanto, sin querer hacer un ejercicio de futurología, el Consejo de Seguridad nos seguirá sorprendiendo con la aprobación de medidas de dudoso acomodo a lo establecido en el Capítulo VII de la Carta y a lo que resulta de una interpretación realizada de acuerdo con la reglas establecidas al efecto por la Convención de Viena sobre el Derecho de los Tratados de 1969.

Lo que parece evidente es que cuanto mayor sea el alcance práctico de las competencias del Consejo de Seguridad más necesario es el establecimiento de controles de legalidad de sus decisiones. En la concepción de futuros controles habrá de ponderar el mantenimiento de la eficacia del Consejo con la legalidad de sus actuaciones. Si bien no podemos arriesgarnos a encorsetar a este órgano de modo que, de nuevo, nos conduzca a la inoperatividad de la que hizo gala antes de la década de los noventa, tampoco podemos mantener la deriva comenzada entonces.

Una cuestión derivada de algunas de las acciones del Consejo de Seguridad en los últimos tiempos es la relación entre la legalidad y la legitimidad de su actuación. Afirmación que podemos ilustrar con un ejemplo reciente: entre las medidas adoptadas este año en relación con Libia destaca la remisión de la situación a la Corte Penal Internacional, que los medios de comunicación europeos han festejado como un triunfo. Jurídicamente la decisión es intachable y encuentra fundamento en el Estatuto de Roma. Pero observemos que sólo dos (Francia y Reino Unido) de los cinco miembros permanentes son partes en el Estatuto de Roma. Los otros tres (Rusia, China y Estados Unidos) han intentado proteger a sus nacionales de la jurisdicción de la Corte Penal Internacional mediante la adopción de resoluciones como la 1422 (2002), del 12 de julio, en la que, con dudosos fundamento en el artículo 16 del Estatuto pide a la CPI ${ }^{106}$ que no inicie ni prosiga investigaciones o enjuiciamiento de ningún tipo contra nacionales (funcionarios o exfuncionarios) de Estados

106 Textualmente indica: "En caso de que el Consejo de Seguridad, de conformidad con una resolución aprobada con arreglo a lo dispuesto en el Capítulo VII de la Carta de las NU, pida a la Corte que suspenda por un plazo de doce meses la investigación o el enjuiciamiento que haya iniciado, la Corte procederá a esa suspensión; la petición podrá ser renovada por el Consejo de Seguridad en las mismas condiciones". 
no partes en el Estatuto que hubieran cometido hechos tipificados en este texto. Considero que esta es una interpretación más que extensiva del Estatuto de Roma que ha llevado a calificar este comportamiento como vulneración y no de mera interpretación del texto en cuestión.

Por si lo anterior no fuera suficiente protección, Estados Unidos ha procedido a un blindaje adicional, más avanzado con su propia legislación interna, adoptando una Ley (American Servicemembers' Protection Act, ASPA) por la que suspende la asistencia económica y militar a Estados partes en el Estatuto que no hubieran celebrado un acuerdo bilateral con Estados Unidos en virtud del cual la eventual entrega de uno de sus nacionales a la Corte se somete a autorización del Estado de nacionalidad. Con lo cual, aunque jurídicamente es adecuada la remisión de los casos a la Corte Penal Internacional por parte del Consejo de Seguridad, no parece del todo correcto que Estados que rechazan abiertamente el ejercicio de la jurisdicción de este Tribunal sobre sus propios nacionales sean quienes decidan principalmente esta cuestión.

De momento nos movemos hacia un sistema de seguridad colectiva que ha cambiado el eurocentrismo característico de la sociedad internacional de antaño por el de los miembros permanentes del Consejo de Seguridad o al menos del que más lo utiliza en defensa de sus propios intereses. A pesar de todo, no es menos cierto que, en ocasiones, con todas las críticas que queramos como la ausencia de sanción a los incumplimientos de sus miembros permanentes o de los aliados más cercanos de estos, el Consejo de Seguridad es lo más avanzado que la sociedad internacional ha conseguido en aras al mantenimiento de la paz y la seguridad internacionales, aunque no nos guste este modelo, de momento, no parecemos estar preparados para otros alternativos que pudiendo ser jurídicamente más apropiados, resulten ineficaces. Aunque deberíamos pensar en establecer mecanismos de control reales y flexibles que permitieran equilibrar la eficacia y el derecho, por la tranquilidad de todos. 